ISSN: 0514-7336

DOI: http://dx.doi.org/10.14201/zephyrus2014744164

\title{
CONTRIBUCIÓN AL ESTUDIO DEL POBLAMIENTO, MODOS DE VIDA Y RITUAL FUNERARIO DEL NEOLÍTICO ANTIGUO: EL ASENTAMIENTO AL AIRE LIBRE DE EL PRADO (PANCORBO, BURGOS)
}

\section{Contribution to the study of settlement, ways of life and funerary ritual in the Early Neolithic: open air settlement El Prado (Pancorbo, Burgos)}

\author{
Carmen Alonso Fernández y Javier Jiménez Echevarría \\ Cronos S.C. Arqueología y Patrimonio. Centro Europeo de Empresas e Innovación, 3. Aeropuerto. 09007 Burgos. \\ Correo-e: tecnicos@cronossc.es
}

Recepción: 20/02/2013; Revisión: 6/07/2014; Aceptación: 15/09/2014

BIBLID [0514-7336 (2014) LXXIV, julio-diciembre; 41-64]

\begin{abstract}
Resumen: La excavación arqueológica realizada en el yacimiento de El Prado ha permitido documentar un asentamiento al aire libre del Neolítico antiguo a partir del registro de casi una treintena de estructuras negativas que formaron parte de un poblado en los inicios del v milenio cal BC. Su situación geográfica en un fondo de valle, junto al desfiladero de Pancorbo, corredor natural aprovechado desde la Prehistoria para conectar el valle del Ebro y la Meseta, explica en parte la elección del asentamiento. Entre las estructuras documentadas destacan varios silos acondicionados con gruesos manteados de barro, un pozo/abrevadero y dos fosas funerarias. Estas últimas suponen, tanto por sus características estructurales como por el ritual, una importante aportación al conocimiento de las prácticas funerarias durante el Neolítico antiguo y vienen a completar el exiguo mapa y la desigual distribución de hallazgos documentados a nivel peninsular hasta finales del v milenio cal BC. El estudio palinológico proporciona interesantes datos sobre las características bioclimáticas y la antropización del medio; y el material arqueológico recuperado pone de manifiesto una clara conexión con los contextos del valle del Ebro, aunque sin ser ajeno a las peculiaridades culturales de la cuenca del Duero.

Palabras clave: Neolítico; Campo de hoyos; Silo; Fosa funeraria; Radiocarbono; Paleoambiente; Península Ibérica; Valle del Ebro; Cuenca del Duero.

AвsтRAct: The archaeological excavation at the site El Prado has documented an Early Neolithic open air settlement and has discovered almost thirty negative structures that were part of an habitat belonging to the early vth millennium cal BC. Its location on a valley bottom beside the gorge of Pancorbo -natural corridor exploited from prehistory times to connect the Ebro valley and the Meseta-, partly explains the location of the settlement. Amongst the documented structures are several storage pits she athed with clay, a well pit and two burials. The latter are both for their structural characteristics and for their ritual, an important contribution to the knowledge of funerary practices during the Early Neolithic, and they will supplement the meagre map and the unequal distribution of findings documented in the peninsula until the end of the vth millennium cal BC. The palynological study provides interesting data on bioclimatic characteristics and anthropization of the environment, and the archaeological material recovered shows clear connections with the contexts of the Ebro valley, but also showing the cultural peculiarities of the Duero basin.

Key words: Neolithic; Rock cut pit settlement; Storage pit; Burial pit; Radiocarbon; Palaeoenvironment; Iberia; Ebro valley; Duero basin.
\end{abstract}




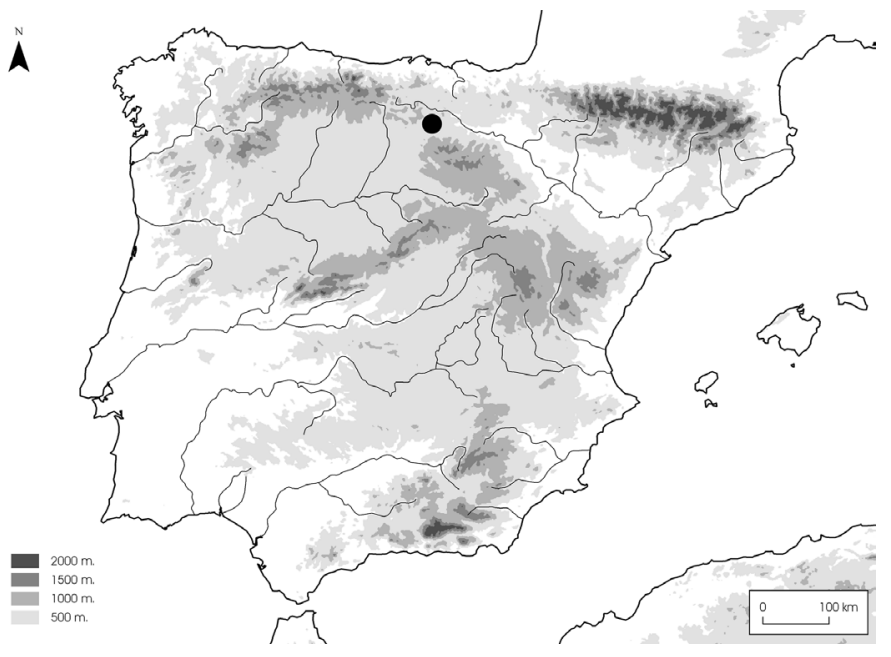

Fig. 1. Localización del yacimiento arqueológico El Prado (Pancorbo, Burgos).

\section{Introducción}

El yacimiento arqueológico de El Prado de Pancorbo (Burgos) se localiza en el extremo NE de la depresión tectónica de La Bureba, en la antesala del profundo y sinuoso desfiladero abierto por el río Oroncillo en los Montes Obarenes, paso natural a la llanada mirandesa que se abre a la región biogeográfica del valle del Ebro desde la Meseta (Fig. 1). Dentro del variado mosaico de ambientes de este territorio, se ubica en un contexto de fondo de valle, donde los suelos son más profundos, a $190 \mathrm{~m}$ de la margen derecha del cauce del río y al pie de un conjunto de pequeńos relieves que lo delimitan al s, encontrándose inmediato al corredor natural que determina este paso en el Sistema Ibérico. El ámbito está modelado por una intrincada red fluvial menor, con distintos arroyos que conforman valles de escasa amplitud, localizándose el asentamiento en el interfluvio de dos de estos, uno ya desaparecido. En su entorno inmediato se intuye también la existencia de pequeñas zonas húmedas y paleocauces a partir de acumulaciones sedimentarias de carácter orgánico identificadas en las proximidades, si bien de cronología incierta, situación en la zona de cauce extraordinario avalada por un pequeño nivel aluvial que cubre parte del registro arqueológico.
La excavación arqueológica se ha realizado sobre una superficie de $1805 \mathrm{~m}^{2}$, permitiendo documentar el sector meridional del asentamiento. Teniendo en cuenta las importantes alteraciones que ha sufrido este ámbito en los últimos años, derivadas de su carácter de corredor natural, es difícil determinar la superficie real del enclave que, de cualquier modo, en origen no debió alcanzar la media hectárea. Como resultado han sido documentadas 29 estructuras negativas entre silos, fosas/cubetas, fosas funerarias y un pozo/abrevadero, agrupadas en dos focos próximos entre sí que se circunscriben a un afloramiento de limos donde se inserta una veta rocosa margo-caliza, dentro de un contexto de lutitas grisáceas que conforman el principal sustrato del entorno inmediato, el cual ha sido evitado (Fig. 2). No están presentes otras estructuras inherentes a la propia actividad habitacional como hogares, fondos de cabaña y hoyos de poste, quizás alteradas por el laboreo agrícola al responder a menudo con estructuras más someras.

\section{Las estructuras negativas}

\subsection{Silos}

Se incluyen aquí 7 estructuras -24,14\%- con rasgos que permiten una atribución segura como contenedores de almacenamiento, principalmente de cereal. Frente al resto, comparten una mayor potencia, revestimientos y manteados de barro en paredes y/o fondo para su aislamiento, y la utilización preferente del soporte geológico rocoso en oposición al dominante de limos.

A excepción de la estructura E-03, que se analiza posteriormente por sus particulares características, el resto responden a fosas de planta circular con sección troncocónica y diámetros entre 145-157 cm, en los que el espesor de los revestimientos interiores reduce notablemente su capacidad e incrementa la proyección troncocónica de la sección. Como primera característica, los revestimientos no fueron aplicados a ras de la estructura, sino que lo hacen desde el tercio superior de la pared, y únicamente en un caso se limita al fondo. Están conformados por arcillas de matriz plástica, con espesores entre 
8-12 cm aplicados en una o dos capas. En este último caso se combinan barros de tonalidad blanquecina y marrón -frecuentemente los claros aplicados a paredes de matriz rocosa y los oscuros a otras de menor consistencia (gravas, limos)-, que pueden entenderse como eventos de mejora (Fig. 3). Sin duda, su considerable grosor está relacionado con el rápido afloramiento del nivel freático propio del ambiente de vega, aspecto que pudimos comprobar durante la propia intervención arqueológica a mediados de otoño.

Otro aspecto morfológico propio es la existencia de una bancada o plataforma lateral de poca profundidad, que prolonga el perímetro

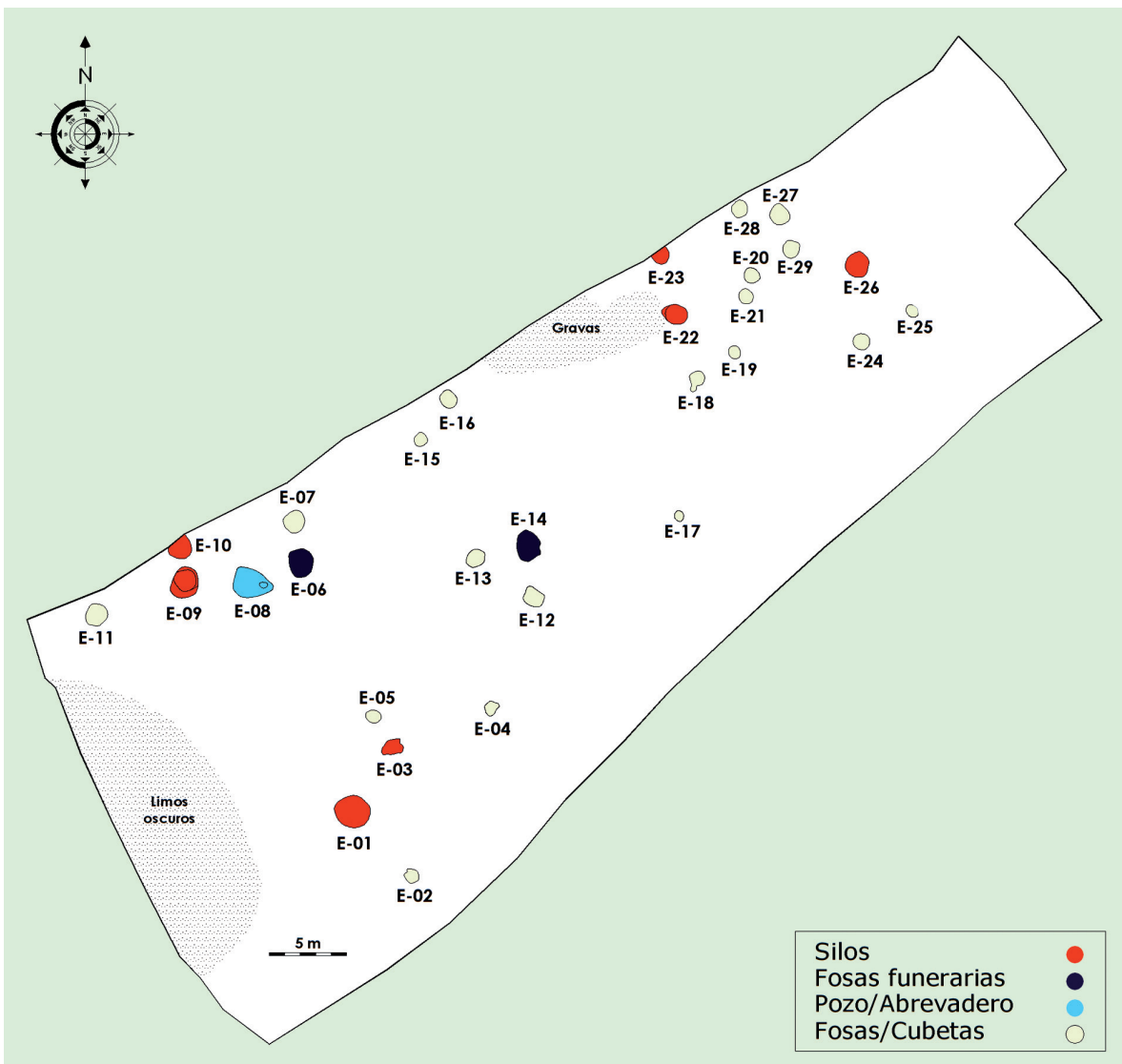

FIG. 2. Planta de la excavación arqueológica y tipología de las estructuras negativas documentadas. como una 'visera'. No es casual que mayoritariamente estas superficies no presenten las paredes revestidas, lo que se traduce en que los manteados no arrancan del mismo borde, quizás porque los silos contaron con tapaderas móviles que aislaban su contenido. Estas plataformas se interpretan como un espacio auxiliar a la función de almacenaje, tal y como ha sido identificado en otros 'campos de hoyos' como en el yacimiento burgalés Llano las Peñas (Modúbar de la Cuesta), donde fue recuperada una vajilla integrada por 18 piezas completas y perfectamente apiladas, asociada en este caso a un momento Protocogotas (Alonso y Jiménez, 2012).

En su conjunto, la arquitectura de este grupo de silos permite interpretar su destino como contenedores de medio y largo plazo, orientados a la reserva de grano para alimento, comercio o sementera con condiciones ambientales estables que no aconsejan su apertura periódica (Buxó, 1996: 180).

Concebidas para el almacenamiento, una vez perdida esta funcionalidad las estructuras fueron amortizadas como basureros; aunque frente a esta interpretación tradicional, otras defienden que el relleno evidenciaría la realización de ceremonias orientadas a la cohesión grupal en las que los actos votivos o los banquetes tendrían un particular protagonismo (Márquez, 2001; Rojo et al., 2008). A juzgar por la homogeneidad de los rellenos, en El Prado estos eventos fueron rápidos, tal y como así denuncia también el registro palinológico, aunque se constatan determinados hiatos intermedios que indican que la amortización se produjo en dos fases, o bien ambas antrópicas, o bien antrópica y natural combinadas.

El silo E-03 merece comentario aparte (Fig. 3). Se trata de un vaciado en ' $L$ ' que en el resto del hoyo fue completado de forma irregular. La pared 

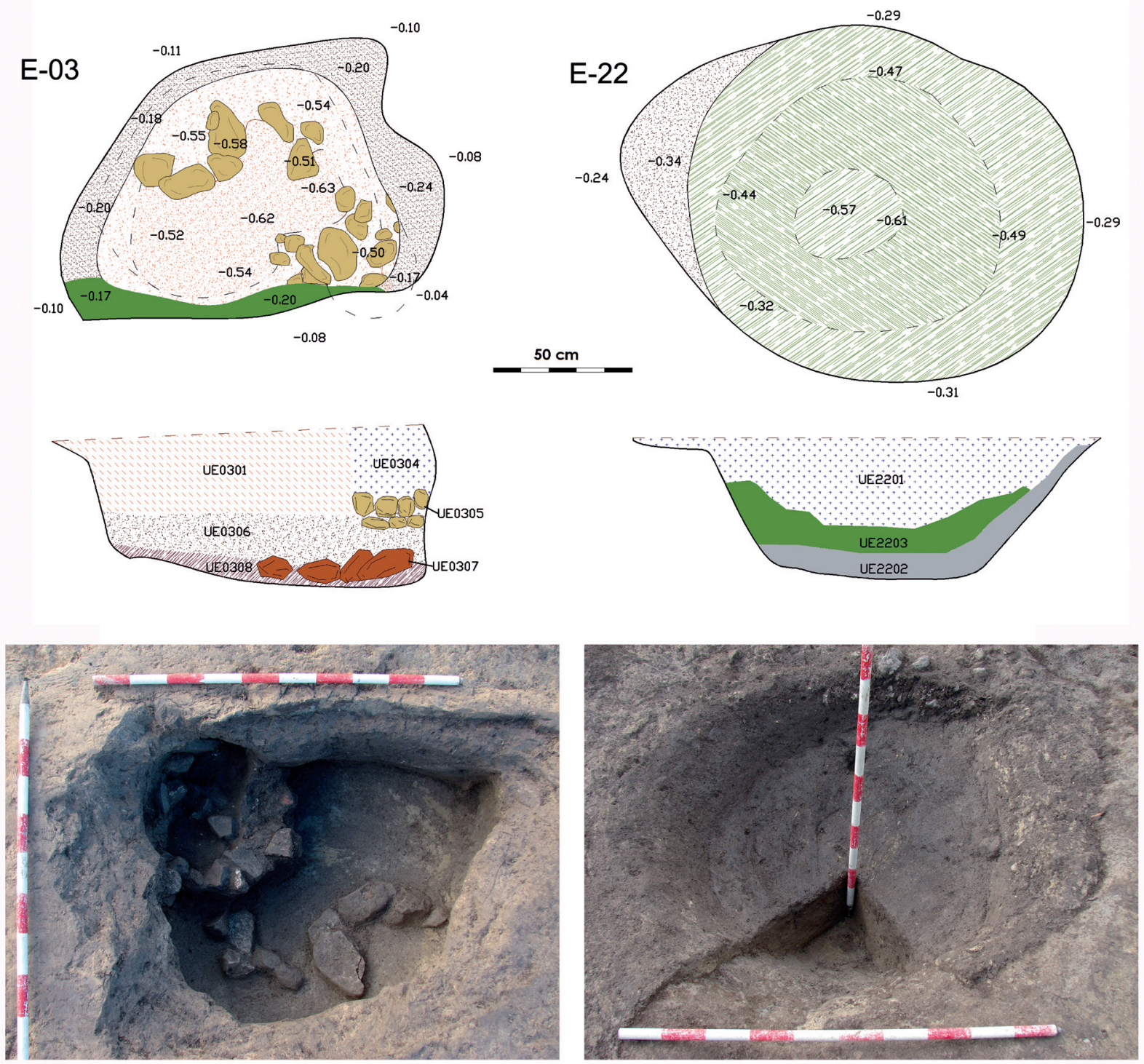

FIG. 3. Plantas y secciones O-E de los silos de almacenamiento E-O3 y E-22.

meridional, la más larga y rectilínea, está conformada a partir de un corte perfecto revestido por un manteado de barro que, una vez más, no arranca de la rasante sino unos centímetros más abajo. El revestimiento se interrumpe en la esquina suroriental donde se abre una cavidad reentrante de desarrollo globular, que cuenta con un círculo de piedras en la base sustentado a su vez por un encachado que también delimita un ligero bancal más profundo. El conjunto fue regularizado con un sedimento de matriz geológica que proporciona aspecto de silo convencional a la pared norte. Interpretamos la estructura como un lugar de almacenamiento de corta duración, quizás de uso cotidiano, destinado a alojar grandes vasos cerámicos de fondo cónico y cuerpo ovoide, de los que han sido recuperados varios fragmentos dentro de la propia estructura. Este tipo de recipiente requiere de una base de sustentación estable, función que cumpliría el mencionado círculo de piedras, y un acomodo en la pared en 
forma de cavidad reentrante para asegurar su verticalidad. Nuevamente, la posición del revestimiento frente al corte superior sugiere que tuvo una cubierta móvil.

La distribución topográfica de los silos determina en gran medida los dos focos en los que se organiza el yacimiento: el oriental, con tres estructuras seguras, y el occidental con cuatro; quizás en orden a la posición de las estructuras de habitación propiamente dichas.

\subsection{Fosas/cubetas}

Las 19 estructuras constituyen el tipo más abundante $-65,52 \%$-, cuya caracterización desde el punto de vista funcional resulta compleja, ya que responden a fosas de escasa potencia, entre 8 y 24 $\mathrm{cm}$. Las plantas muestran gran variabilidad, siendo las mejor representadas las circulares $-47,37 \%-$ y ovo-circulares - $31,58 \%$-, frente a ovales $-15,79 \%-$ y lobuladas -5,26\%-; y sus diámetros oscilan entre los $72-145 \mathrm{~cm}$. Las secciones son cuenquiformes, aspecto explicable por el arrasamiento superficial.

Frente a lo que ocurre en el grupo de silos, en general están excavadas en el soporte de limos que domina la litología del enclave, siendo infrecuentes en sustrato rocoso. En algunos casos se pone de manifiesto que este ha sido evitado intencionalmente, puesto que el fondo de varias fosas responde a la propia superficie de la veta de roca. Buena parte se encuentran amortizadas como basureros $-68,42 \%-$, encontrándose colmatadas por rellenos cenicientos y/o de matriz orgánica. Las secuencias de relleno son rápidas, normalmente una o dos, habitualmente coincidiendo con acciones combinadas de origen antrópico y natural, aunque en cuatro fosas se produjo exclusivamente por acción natural.

Dentro de la complejidad que supone su interpretación, nos inclinamos a pensar que se trata de fosas con funcionalidades variadas -trasvase de alimentos, despensas temporales e incluso letrinas-, ya que queda patente que el grupo de silos cuenta con unas características morfométricas, de soporte y estructurales bien diferentes. No se aprecia tampoco un patrón concreto de organización espacial dentro del yacimiento por cuanto se intercalan entre los silos del sector oriental, pero no lo hacen así en el occidental, apareciendo también en la zona de dispersión entre ambos.

\subsection{Fosas funerarias}

Entre las estructuras documentadas tienen un especial interés dos fosas funerarias -E-06 y E-14enclavadas entre el resto de las estructuras negativas del yacimiento, en el sector occidental, mediando $13 \mathrm{~m}$ de separación entre una y otra. De este modo, aunque se trata de tumbas individuales, conservan el vínculo con la colectividad al emplazarse en el mismo espacio que ocupa el poblado.

\subsubsection{Características morfológicas y estratigráficas}

Ambas fosas tienen plantas de tendencia oval y diámetros absolutos prácticamente iguales $-197 \mathrm{x}$ $154 \mathrm{~cm}$ en E-06 y 203 x $154 \mathrm{~cm}$ en E-14-, excavadas en limos. Su morfología interior es compleja, ya que están organizadas mediante una sucesión de pequeños bancales entallados que, a modo de escalones, dan acceso al receptáculo o cámara funeraria propiamente dicha, al s en la fosa E-06 y al $\mathrm{N}$ en E-14. Igualmente se observa la colocación premeditada de piedras que de algún modo individualizan el receptáculo funerario del resto de la fosa, existiendo diferencias estratigráficas entre los sedimentos que rellenan ambos ambientes (Fig. 4).

La fosa E-06 presenta un diámetro regular de entorno a $150 \mathrm{~cm}$, pero hacia el s se desarrolla una superficie arrellanada o plataforma en forma de 'visera', hoy de escasa profundidad y similar a la documentada en los silos, que le proporciona un diámetro máximo cercano a los $2 \mathrm{~m}$. De $\mathrm{N}$ a s aumenta progresivamente la profundidad mediante el entallado de dos plataformas que, a modo de escalones, permiten el acceso al interior del receptáculo funerario. Acompañando a estos, principalmente en relación a las aristas de los entalles, fueron colocadas numerosas lajas de piedra de tamaño variable. El receptáculo alcanza una potencia de $56 \mathrm{~cm}$ y forma de tendencia ovalada, de $82 \mathrm{~cm}$ de longitud -E-O- y hasta $52 \mathrm{~cm}$ de anchura - $\mathrm{N}$-S- aunque, como se verá más adelante, únicamente parte de los restos del inhumado han sido documentados en su interior. Con respecto al proceso de colmatación, hay un sedimento asociado al receptáculo funerario -de color gris oscuro pero carente de ceniza o carbón-, otro a los dos escalones y un tercero que colmata definitivamente la estructura incluida la plataforma lateral. 

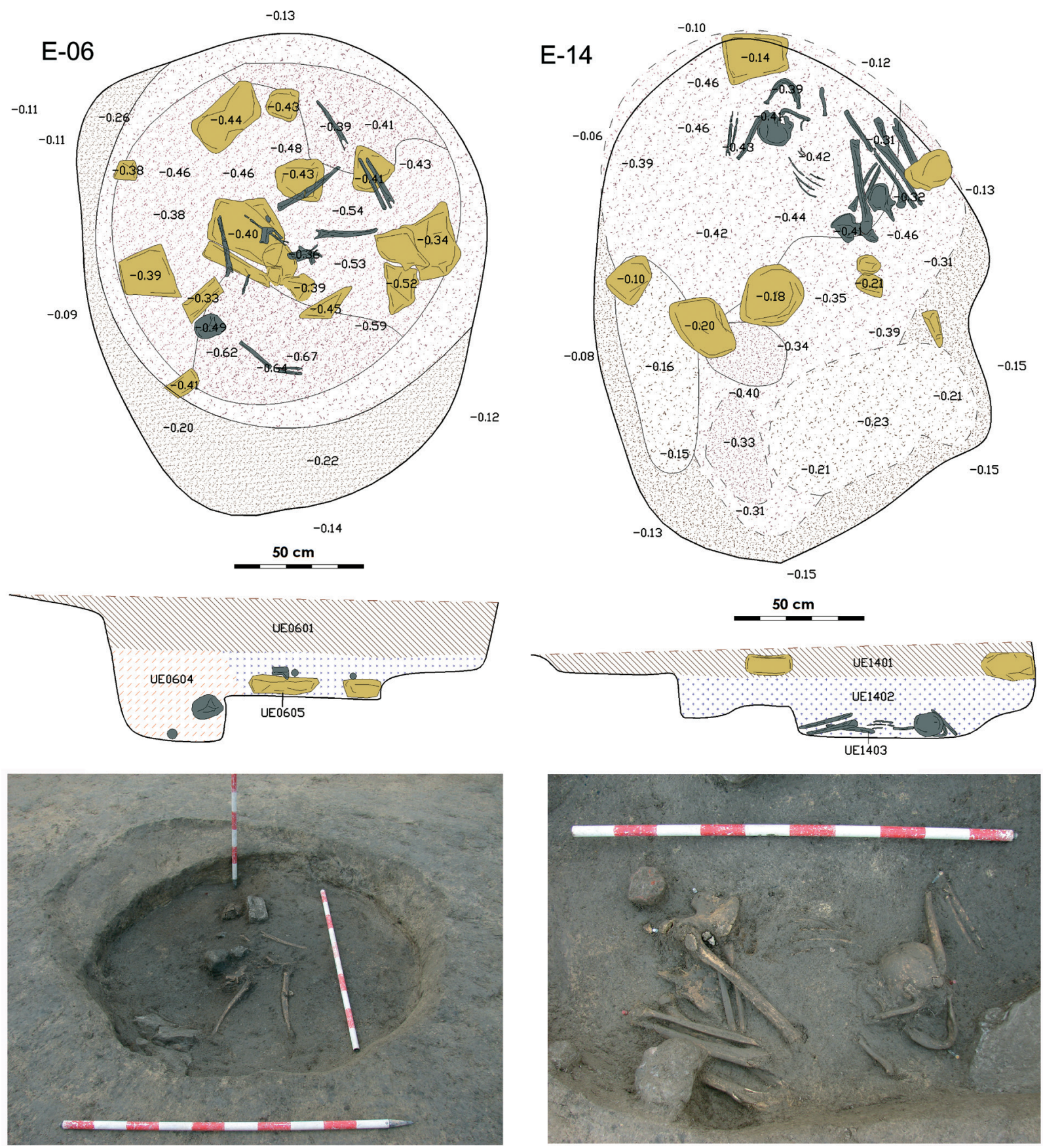

Fig. 4. Plantas y secciones (S-N y SE-NO) de las fosas funerarias E-OG y E-14.

Por su parte, la fosa E-14 es de forma ovalada, de $203 \mathrm{~cm}$ de diámetro $\mathrm{N}-\mathrm{S}$ y $154 \mathrm{~cm}$ E-O. En este caso, el incremento progresivo de la profundidad se produce en sentido contrario, de $\mathrm{s}$ a $\mathrm{N}$, mediante el entallado de tres plataformas, dos consecutivas y una tercera situada en el flanco o, entre las que media una pequeña rampa en forma de canal igualmente escalonado. El receptáculo funerario ocupa prácticamente 
la mitad de la estructura y presenta perfil globular, posiblemente con la finalidad de incrementar la protección del difunto. Tiene $117 \mathrm{~cm}$ en el eje E-O y 103 $\mathrm{cm}$ en el N-s, con una profundidad de $39 \mathrm{~cm}$. Para individualizarlo de las plataformas entalladas fueron colocadas un conjunto de piedras entre las que se encuentran tres molinos de mano. El proceso de colmatación se llevó a cabo mediante un sedimento asociado a la cámara funeraria -con abundante ceniza y carbón-y otro que lo cubre y completa el relleno del resto de la estructura.

\subsubsection{Las inhumaciones y el ritual funerario}

En el interior de las fosas fueron inhumadas dos mujeres adultas cuya edad de muerte ha sido estimada en 40-45 años -fosa E-06- y en 48-56 años -fosa E-14-. Ambos cuerpos fueron manipulados antes de recibir sepultura definitiva, momento en el que conservaban ciertas conexiones anatómicas. Esta valoración se fundamenta en el análisis de la naturaleza de las conexiones a partir de los diferentes procesos que las condicionan, relacionados con las prácticas preparatorias, sepulcrales y postdeposicionales, y por los agentes naturales químicos, biológicos y mecánicos (Armentano, 2012; Duday, 2009). La descomposición puede provocar movimientos postdeposicionales y la pérdida de vínculos anatómicos, en particular si tiene lugar en vacío, produciendo el desplazamiento gravitacional, pero, en nuestro caso, se observan desconexiones en las articulaciones permanentes que sin embargo no están presentes en las de naturaleza lábil, en concreto en el carpo, únicas conservadas a falta de tarsos y cervicales. Por otro lado, los cráneos conservan la articulación temporomandibular y en E-14 no hay desarticulación en las extremidades inferiores. La manipulación de los cuerpos parece que tuvo lugar en el interior de las propias estructuras, como apuntan la existencia de receptáculos funerarios y las evidencias sedimentarias, de modo que cuando fueron realizadas las recolocaciones ya se encontraban en su interior. Lógicamente no se puede descartar que inicialmente fuesen depósitos secundarios, pero en tal caso se habrían sucedido tres eventos de depósito.

La mujer de la fosa E-06 fue inicialmente depositada en el interior del receptáculo funerario, como indica el importante aporte orgánico que presenta el sedimento. Cuando el proceso de descomposición era avanzado, fue recolocada en la zona central de la estructura, de modo que solo el cráneo y el brazo izquierdo permanecieron en el interior del lugar de alojamiento primitivo. Los restos no aparecieron depositados en el fondo de la estructura, como es lo habitual, sino entre un importante volumen de sedimento y con gran variación de cota entre ellos. El cráneo, por ejemplo, apareció a una profundidad de $27 \mathrm{~cm}$, en un ámbito en el que el receptáculo alcanza los $56 \mathrm{~cm}$ de potencia, $10 \mathrm{~cm}$ por debajo se localizó el brazo izquierdo, y otros $10 \mathrm{~cm}$ por encima el derecho. No hay restos de vértebras ni de cintura escapular, aunque de conservarse difícilmente existiría conexión con el cráneo y las extremidades. $\mathrm{Al}$ haber sido colocado a diferentes niveles, el cuerpo presenta una postura forzada incrementada por estar parcialmente sobre las piedras. Fue depositado en decúbito prono, con orientación sO-NE, el brazo derecho flexionado bajo el abdomen y el izquierdo estirado pero con ligera flexión. La inconexión de los restos también es visible en la articulación del codo derecho, al tiempo que la flexión de las piernas, claramente forzada, exige la dislocación de las rodillas, no atribuible a desplazamientos causados por el proceso de descomposición que producen la parcial desvinculación en la articulación.

La mujer de la fosa E-14, de la que la causa de muerte más probable fue un trauma en la región frontal del cráneo, pudo ocupar inicialmente un espacio mayor del receptáculo. Particularmente significativo es el componente mixto del sedimento de relleno y de cubrición del cuerpo ya que, aunque netamente ceniciento y carbonoso, presenta mezcla de material geológico que indica la reapertura de la fosa. Finalmente fue depositada en posición flexionada en la zona oriental del nicho, con orientación NO-SE, el cráneo desconectado del resto del cuerpo, ya que no hay restos de cervicales, y violentamente girado y volteado hacia la izquierda. La conexión del resto del cuerpo parece mayor que en el caso anterior; fue dispuesto en decúbito supino con los brazos flexionados, el derecho hacia atrás, por encima del cráneo, y el izquierdo sobre el abdomen. Después, se procedió a flexionar las piernas hacia el tronco y a rotarlas hacia el lado izquierdo.

Con respecto a la presencia de ajuares funerarios, cabe mencionar que en ambas fosas han sido 
recuperados algunos materiales arqueológicos cuya presencia no tiene por qué estar necesariamente relacionada con una intencionalidad votiva, ya que pudieron ser introducidos de manera fortuita formado parte del sedimento de relleno. El conjunto, sin embargo, es numéricamente significativo con respecto a la totalidad del material recuperado, ya que representa el $12,44 \%$ del material lítico y el $15,95 \%$ del cerámico. En E-14 abundan los restos óseos faunísticos, particularmente de ciervo; de hecho, la fauna escasea en el yacimiento, pero aquí es particularmente abundante, por lo que su presencia podría estar relacionada con la práctica del 'banquete funerario'. Además, en esta misma estructura han sido recuperados los ya mencionados molinos de mano y una azuela pulimentada de ofita situada junto al brazo derecho, único elemento que mantenía contacto directo con el cuerpo, piezas frecuentemente asociadas a contextos funerarios y que en este caso cobran un interés particular. El abundante utillaje lítico en sílex está integrado principalmente por laminillas y láminas, entre las que destaca un diente de hoz con truncadura oblicua y 'lustre de cereal' (Fig. 8, n. ${ }^{\circ}$ 19). En la estructura E-06 podría individualizarse una laminilla retocada que fue recuperada junto al cráneo (Fig. 8, n. $^{\circ} 3$ ) ya que, como sucede en el caso anterior, el resto de material apareció entre los distintos rellenos sedimentarios.

La configuración de las fosas se ajusta a una práctica estandarizada, tanto en cuanto a dimensiones como a morfología. Son estructuras construidas ex profeso con finalidad funeraria, con la peculiaridad de contar con un receptáculo o cámara destinada a alojar el cadáver al que se accede a través de pequeñas plataformas entalladas en el sustrato geológico. Estos entalles pudieron jugar un papel importante durante la primera fase ritual, cuando los cuerpos fueron depositados en el receptáculo a la espera de su parcial descomposición. Durante este tiempo la superficie ocupada por las plataformas escalonadas debió permanecer sin colmatar, lo que permitiría el acceso a la cámara y facilitaría el posible depósito de ofrendas. Aunque cabe la posibilidad de que la totalidad de la estructura permaneciera abierta, las características sedimentarias de la fosa E-14 parecen indicar lo contrario.

En una segunda fase, cuando presentaban un alto nivel de descomposición pero conservaban ciertas conexiones anatómicas, los cuerpos fueron desenterrados y recolocados, y las fosas definitivamente colmatadas. Esta práctica cabe enmarcarla en los denominados 'ritos de paso', en los que se espera a la descarnación de los cuerpos para que el alma abandone el mundo de los vivos, momento en el que puede recibir sepultura definitiva (Metcalf y Huntington, 1991: 84 y ss.). Aunque a lo largo del Neolítico no es rara la documentación de restos óseos en posición secundaria tanto en contextos domésticos como funerarios de tipología variada (Garrido et al., 2012: 146, 148), la manipulación de los cadáveres es mucho más infrecuente, destacando los casos constatados en las fosas funerarias de los yacimientos levantinos de Costamar, de principios del v milenio cal BC, y La Vita, del Neolítico Final (Bernabeu, 2010: 52). En un ámbito geográficamente más próximo se sitúa la necrópolis de Paternanbidea, donde han sido documentadas diferentes manipulaciones en los cuerpos (García, 2007), destacando la coexistencia en una misma fosa de enterramientos dobles simultáneos con otros acumulativos, manipulaciones que pudieron ser debidas a la necesidad de alojar nuevos cuerpos o al traslado a nuevas fosas.

\subsection{Pozolabrevadero}

En el sector occidental del yacimiento se ha documentado una estructura -E-08-, colmatada fundamentalmente por acción natural, cuya interpretación podría asimilarse a un sistema vernáculo de recogida y mantenimiento de agua, especialmente efectivo en épocas de cierto estiaje (Fig. 5). Se trata de una fosa de tendencia trapezoidal y orientación este-oeste, de 267 x $191 \mathrm{~cm}$, tallada en el sustrato de roca. Las paredes son tendidas, presentado mayor profundidad en el extremo occidental, que no supera los $20 \mathrm{~cm}$. En el extremo opuesto, donde hay una ruptura litológica entre limos y margas, existe una fosa oval de $52 \times 40 \mathrm{~cm}$, y desarrollo globular con el plano de inclinación excéntrico, que penetra en el sustrato geológico 41 $\mathrm{cm}$ más. Junto a esta subestructura se advierte un ligero canalillo entallado en la roca, en su conjunto vergente hacia el o.

Según la experiencia comentada en los silos, la fosa interior alcanzaría el nivel freático, quedando resguardada la lámina de agua por el desarrollo 
inclinado de la estructura, lo que evitaría su evaporación y la pérdida de calidad. En caso de rebosamiento natural en épocas de menor estrés hídrico, o por iniciativa de los pobladores, el excedente podría ser vertido a la amplia cubeta superficial posibilitando un uso como abrevadero.

Este tipo de estructuras, aunque poco frecuentes, se han documentado como soluciones vernáculas en asentamientos con recursos hídricos limitados, como el poblado del Bronce Antiguo de Los Baldios (Castejón del Campo, Soria), donde mediante tres hoyos similares se recogía el agua de un paleocauce ${ }^{1}$.

\section{Materiales arqueológicos}

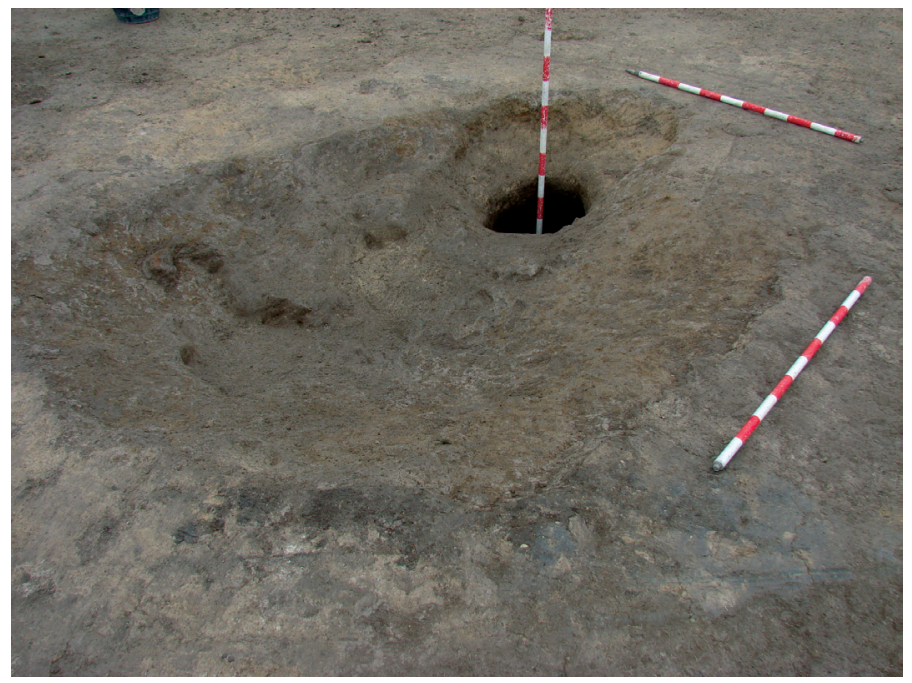

FIG. 5. Estructura E-08, interpretada como pozolabrevadero.

\subsection{La cerámica}

El material cerámico está integrado por 821 fragmentos que suman un peso total de $7716 \mathrm{~g}$, lo que pone de manifiesto la elevada fragmentación del conjunto, algo frecuente en este tipo de contexto arqueológico. Esta circunstancia ha condicionado el análisis de la colección sobre todo en cuanto a características formales se refiere, ya que, aunque ha sido establecido un número de 42 piezas, únicamente 9 corresponden a perfiles parciales.

Desde el punto de vista técnico el conjunto ha sido modelado con pastas sedimentarias en las que predomina la cuarcita de granulometría fina y media. También es frecuente la adición de chamota, sobre todo de calibre medio y grueso, y ocasionalmente se observan caliches cuarcíticos, mientras que carbonatos y mica aparecen con carácter testimonial. Con respecto a la cocción, hay un predomino de la reductora y de la reductora con postcocción oxidante. El tratamiento superficial predominante es el alisado, aunque en el 19\% de las piezas se encuentra próximo al bruñido. El porcentaje de piezas con aguadas o engobes asciende al 7,14\%, ligeramente superior cuando se analiza por fragmentos $-7,67 \%-$. El escobillado interior representa poco más del $2 \%$, y existe un único fragmento espatulado.

1 Cronos s.c. (2012): Excavación y documentación arqueológica del yacimiento "Los Baldios" de Castejón del Campo (Almenar, Soria). Informe inédito.
El repertorio formal se inscribe en las tipologías habituales descritas para los conjuntos neolíticos peninsulares, pudiendo tomar como referencia la definida en la cueva segoviana de La Vaquera (Estremera, 2003). Está integrado principalmente por recipientes de tamaño medio, de entre 13 y $25 \mathrm{~cm}$ de diámetro, pertenecientes a perfiles simples que parten de formas esféricas u ovoides. Dentro de los identificados, los recipientes en forma de casquete esférico asimilables a la forma III de La Vaquera están bien representados, caracterizados por presentar escasa altura en relación al diámetro del borde (Fig. $6,{ }^{\circ}{ }^{\text {s }} 6$ y 9), destacando una pieza con el labio acanalado que le proporciona apariencia moldurada (Fig. 6, n.o 1). Dos de estos recipientes están decorados, aunque destaca un cuenco, único ejemplo de boquique (Fig. 7, n. ${ }^{\circ}$ 3); el otro incorpora impresiones seriadas sobre el labio y orejeras aplicadas (Fig. 6, n. ${ }^{\circ}$ 9).

Se cuentan tres perfiles hemisféricos abiertos asimilables a la forma I de La Vaquera (Fig. 6, n. ${ }^{\text {s }}$ 2-3). Posiblemente es la forma más abundante, si tenemos en cuenta la tendencia en el desarrollo de las paredes de otros bordes recuperados. Ente los perfiles destaca un recipiente provisto de asa de cinta (Fig. 6, n. ${ }^{\circ}$ 5).

$\mathrm{Al}$ menos hay siete recipientes de tendencia cerrada (Fig. 6, n. ${ }^{\circ}$ 7) -forma II de La Vaquera-, aunque tan solo ha sido identificado un perfil parcial con orejeras dobles aplicadas en el labio y en 

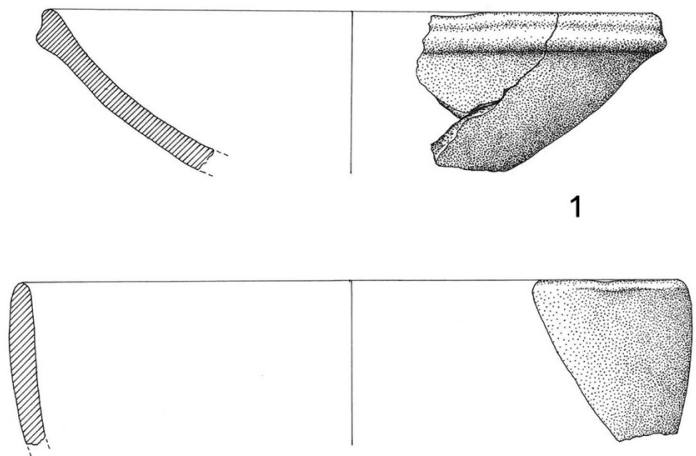

3
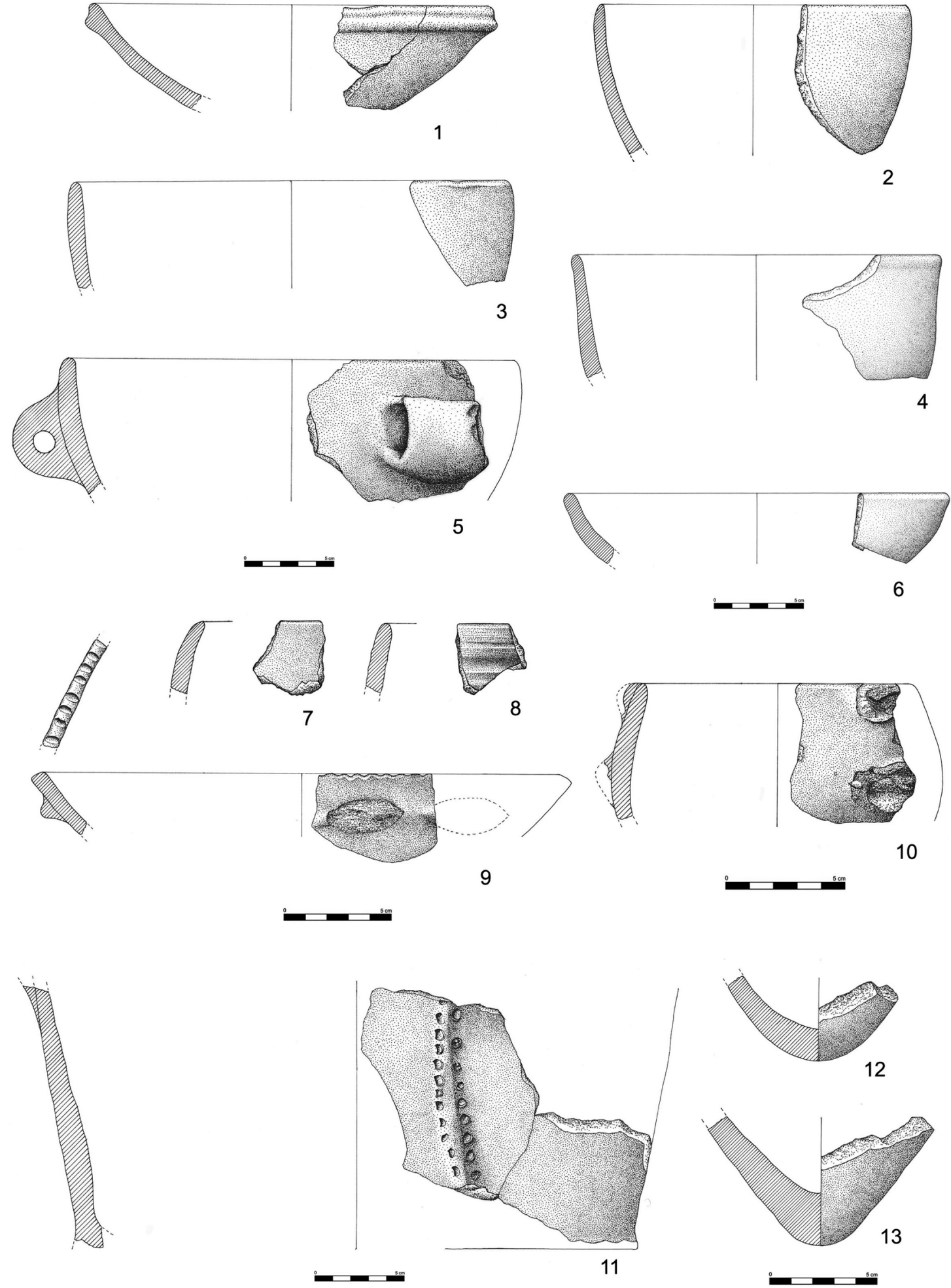

Fig. 6. Materiales cerámicos (dibujo: Belén Alonso). 

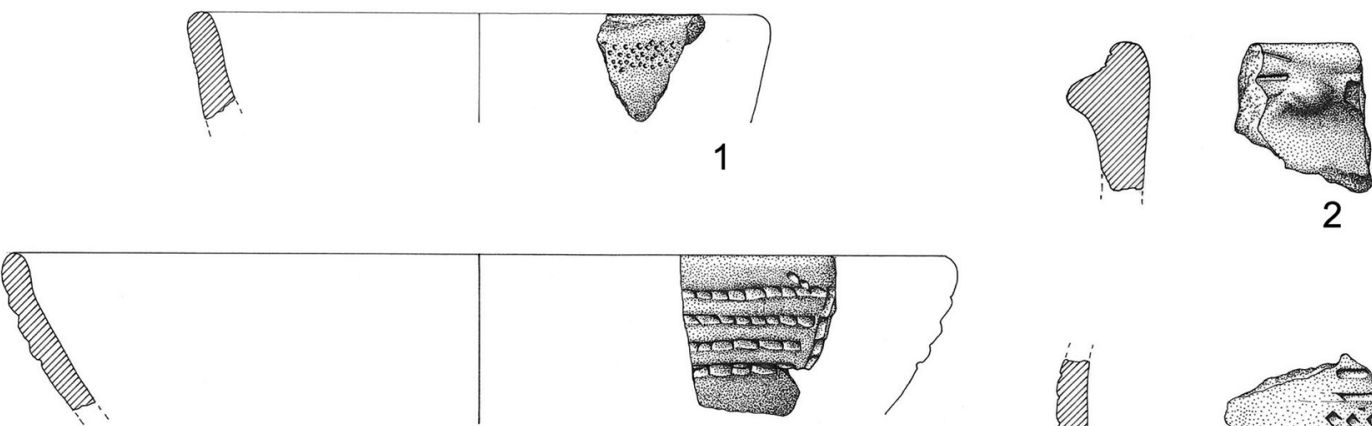

3
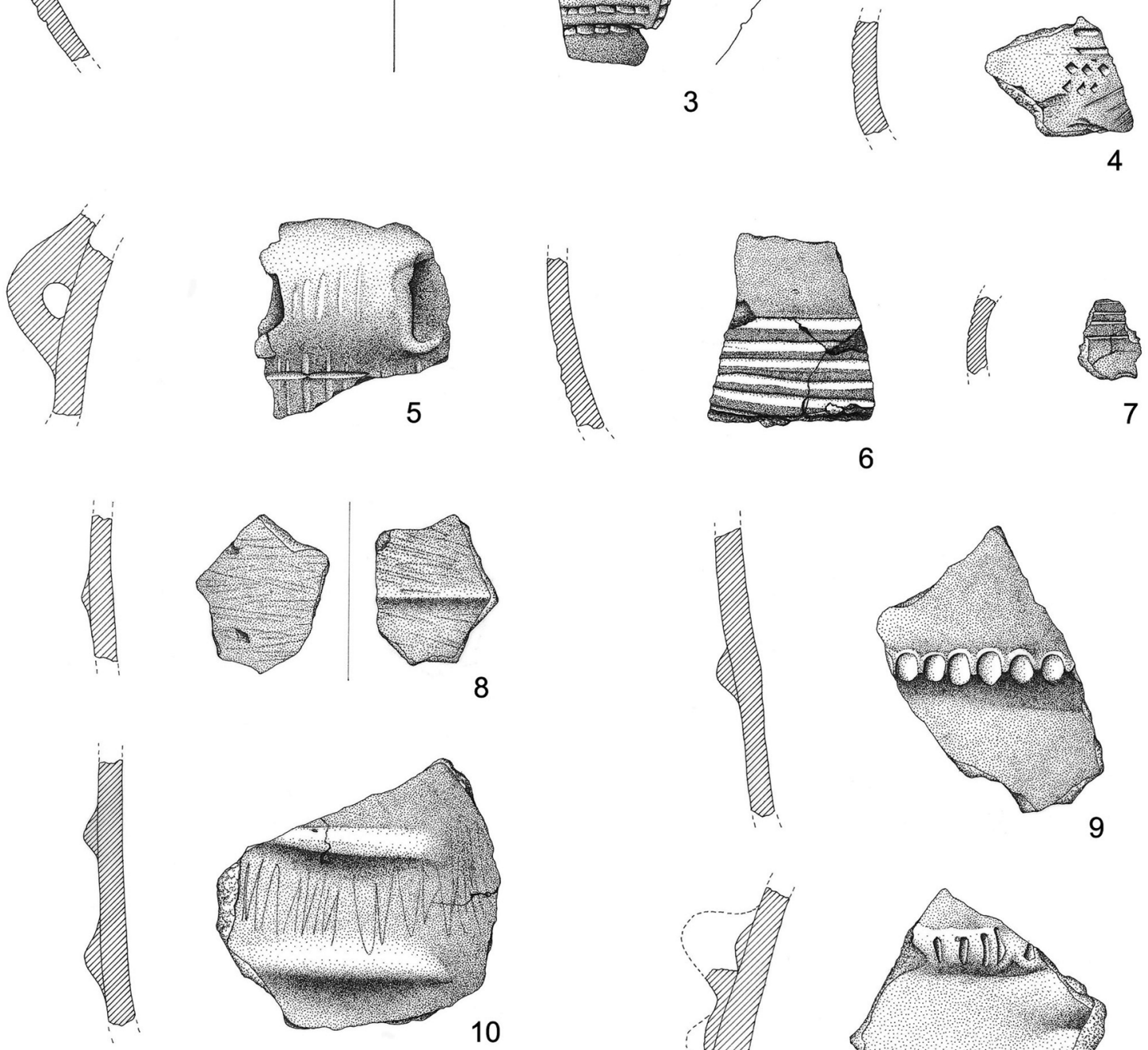

10
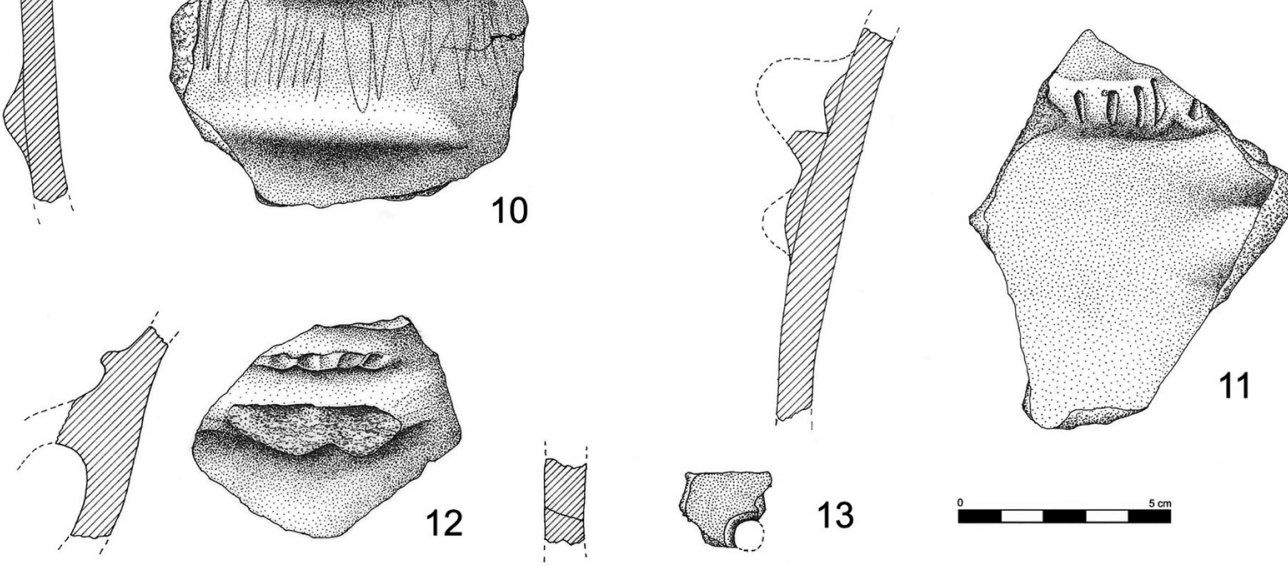

13

Fig. 7. Materiales cerámicos (dibujo: Belén Alonso). 
la panza (Fig. 6, n. ${ }^{\circ}$ 10). El último perfil superior identificado se corresponde con la forma IV del yacimiento segoviano, un recipiente con paredes de desarrollo recto pero labio ligeramente exvasado (Fig. 6, n.o 4).

Los fondos cónicos (Fig. 6, n. ${ }^{\text {os }} 12-13$ ) ponen de manifiesto la existencia de orzas destinadas al almacenaje de alimentos, que suelen presentar perfiles de desarrollo ovoide -forma v de La Vaquera-. El resto de los fondos identificados son hemisféricos o planos. Por último, cabe mencionar la presencia de un fragmento de borde de desarrollo recto asimilable a una forma cerrada tipo botella y otro de cuello ligeramente marcado que cabría relacionarlo con la forma vi de la referida cueva.

Los elementos de prensión están bien representados, tanto en forma de orejeras como de asas de cinta, con un único ejemplo de perforación (Fig. 7, n. ${ }^{\circ}$ 13) y dos mamelones. Las orejeras aparecen como elementos aislados pero también dobles, bien sobre el labio y la panza (Fig. 6, n. ${ }^{\circ} 10$ ) o sobre el cuerpo (Fig. 2, nos 10-11), incluso seriados bajo el labio (Fig. 6, n. ${ }^{\circ}$ 9); también ha sido documentado un ejemplar segmentado mediante impresión (Fig. 7, n. $\left.{ }^{\circ} 2\right)$. Estos elementos suelen aparecen en recipientes decorados con verdugones. Por su parte, las asas de cinta son anchas y de desarrollo vertical.

El número de fragmentos decorados asciende a 44 aunque, si tenemos en cuenta que varios de ellos pertenecen a la misma pieza, el número se reduce a 29 , un porcentaje bajo que a nivel global de fragmentos representa el 5,35\% de la colección; pero si se toma como referencia el número de bordes, la proporción asciende al 19,04\%. Con respecto a las técnicas, con carácter general se observa un claro predominio de la impresión -39\%- sobre la incisión $-22 \%$-, aunque es la decoración aplicada la que ocupa el segundo lugar -37\%-. El boquique solo está presente en la pieza mencionada $-3 \%-$.

Impresión, incisión y aplicación aparecen tanto como técnicas únicas -62,07\%-, como combinadas -37,93\%-. En el primer caso la incisión es la más abundante -28\%-, con un porcentaje idéntico de motivos acanalados, en forma de suaves ondulaciones (Fig. 6, n. ${ }^{\circ}$ ) o surcos marcados (Fig. 7, n. ${ }^{\circ} 6$ ), que de incisiones de trazo fino en forma de líneas horizontales (Fig. 7, n. ${ }^{\text {os }} 5$ y 7). Incluimos en esta técnica un interesante fragmento con líneas esgrafiadas inscritas entre orejeras (Fig. 7, n. $^{\circ}$ 10).
Igualmente destaca un galbo con asa de cinta decorada con líneas verticales paralelas y, bajo esta, líneas verticales cruzadas por otra horizontal (Fig. 7 , n. ${ }^{\circ}$ 4). También están bien representados los verdugones lisos $-17 \%-$, sin ningún otro tipo de técnica decorativa. Se trata de cordones aplicados horizontalmente sobre las piezas y de escaso resalte (Fig. 7, n. $\left.{ }^{\circ} 8\right)$. La decoración impresa aparece como técnica única $-14 \%-$, por lo general en forma de segmentos o digitaciones aplicadas sobre los labios (Fig. 6, n. ${ }^{\circ}$ 9), aunque destaca el borde de un recipiente de perfil simple abierto que cuenta con una banda de finos puntos dispuestos bajo el labio (Fig. 7, n. ${ }^{\circ} 1$ ).

En lo referente a técnicas combinadas, lo más frecuente es la asociación aplicación-impresión $-35 \%-$, por lo general a base de verdugones decorados con segmentos de matriz apuntada (Fig. 7, n. ${ }^{\circ}$ 11) y menos frecuentemente por digitaciones (Fig. 7, n. ${ }^{\circ} 9$ ); junto con una pequeña orejera decorada con pequeñas impresiones localizada sobre un asa de cinta (Fig. 7 , n. ${ }^{\circ} 12$ ), y un recipiente de almacenaje de fondo plano decorado con verdugón flanqueado por impresiones de tendencia cuadrangular (Fig. 6, n. $\left.{ }^{\circ} 11\right)$. Por último, existe un ejemplo que combina incisión-impresión -3\%- (Fig. 7, n. $\left.{ }^{\circ} 4\right)$.

\subsection{Industria litica tallada}

La materia prima utilizada mayoritariamente es el sílex, aunque hay un conjunto de piezas en cristal de roca $-3,32 \%$ - integrado por laminillas (Fig. 8, n. ${ }^{\circ}$ 12), microlaminillas (Fig. 8, n. ${ }^{\text {os }} 7-8$ ) y un resto de talla. El sílex es de grano fino y buena calidad, presentando tonalidades que van del blanco al negro, pasando por colores rojizos intensos y una amplia gama de melados y grises, tanto lisos como veteados. En cuanto a su procedencia, predominan mayoritariamente los tipos Loza y Treviño, con conocidos afloramientos al sur de Álava y en el Condado de Treviño (Tarriño, 2006) distantes unos $35 \mathrm{~km}$ del yacimiento.

En algo menos del $4 \%$ se observan alteraciones térmicas derivadas del calentamiento controlado de los nódulos de sílex, que se manifiesta mediante microfisuras, pátinas o el característico 'lustre térmico’. A nivel macroscópico también son identificables huellas funcionales relacionadas con el uso de las piezas, destacando dos con 'lustre de cereal' (Fig. 8, n. ${ }^{\text {os }} 1$ y 19 ). 

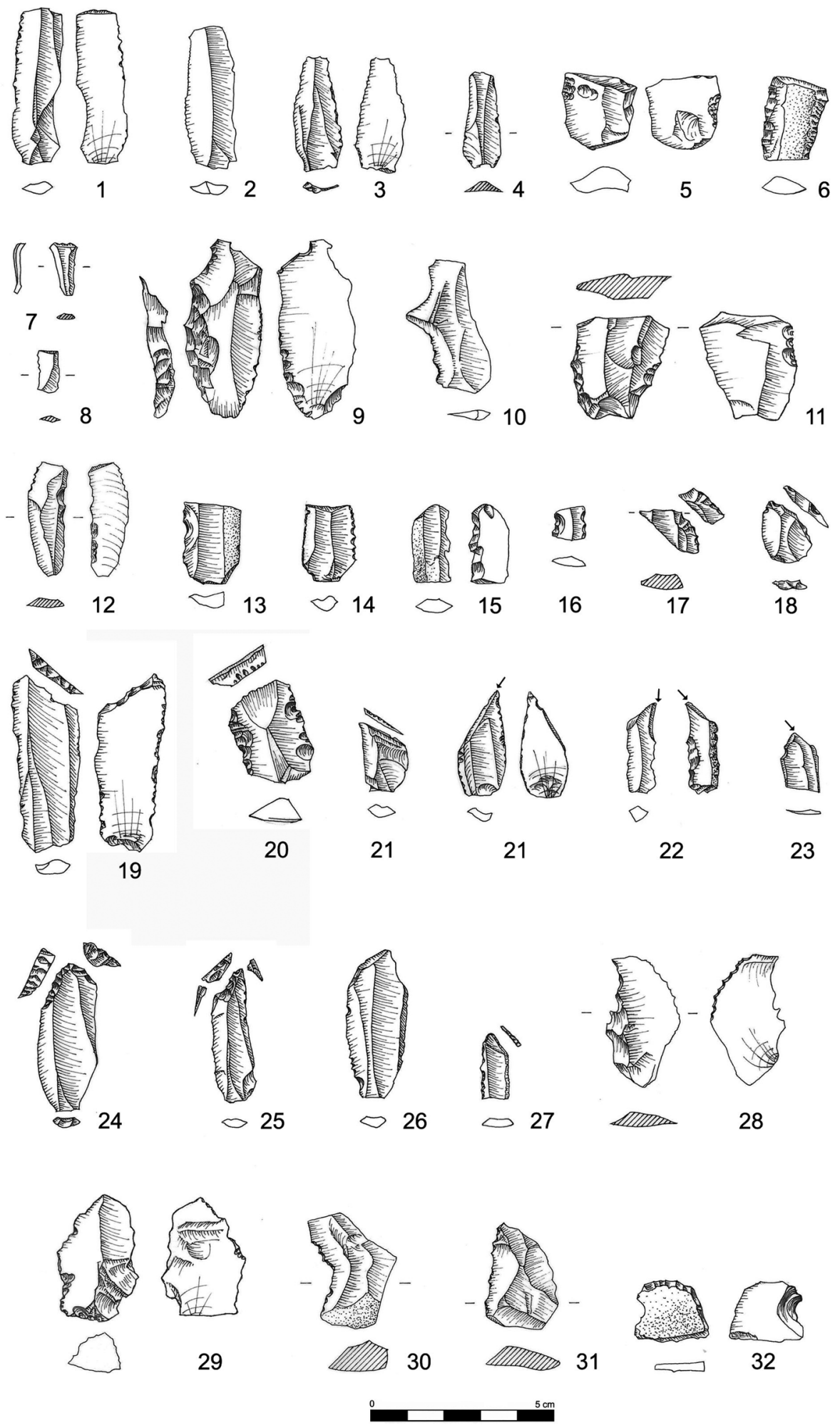

Fig. 8. Industria litica tallada sobre láminas (1-27) y lascas (28-32) (dibujo: Belén Alonso). 
De las 241 piezas recuperadas, 97 están integradas por restos de talla y nódulos de sílex descortezados, lo que supone el $40 \%$ del total. El resto de soportes está mayoritariamente representado por armaduras laminares $-54,17 \%-$, lo que implica una marcada tendencia a la utilización de esta técnica frente al lascado. Las lascas representan el 34,72\%, los núcleos el 6,72\%, las láminas de cresta el 3,47\% y los avivados el $1,39 \%$. Tanto lascas como láminas proceden de núcleos prismáticos y poliédricos (Fig. $\left.9, \mathrm{n} .{ }^{\text {os }} 1-2\right)$, agotados o muy explotados. La presencia de elementos relacionados con la práctica de la industria extractiva indica que la materia prima era trasladada al poblado previamente transformada en núcleos o en nódulos descortezados, y que era aquí donde se llevaba a cabo el proceso de laminación, lascado y retoque. En este sentido, destacan tres piezas recuperadas en la estructura E-16 -una muesca (Fig. 8, n. ${ }^{\circ} 10$ ), una lasca y un resto de talla- procedentes del mismo núcleo de extracción.

Los soportes laminares ${ }^{2}$ están integrados por láminas $-44,58 \%$-, laminitas $-45,78 \%$ - y microláminas -9,64\%-. El porcentaje de armaduras enteras es del $30,12 \%$, repartidas en láminas -8\%-, laminillas $-60 \%-$ y microlaminillas $-32 \%-$. Las fracturas proceden mayoritariamente del seccionamiento de láminas -60\%-, predominando las piezas rectangulares de filos paralelos y sección trapezoidal. Cuando parten de láminas se observa una clara preferencia hacia las proximales, mientras que en las laminillas los porcentajes de distales, mediales y proximales son muy similares. La tipometría se sitúa mayoritariamente entre $10-30 \mathrm{~mm}$ de longitud y $10-20 \mathrm{~mm}$ de anchura, pero cuando se utiliza la anchura como único criterio de análisis englobando tanto armaduras enteras como fracturadas, y estableciendo los $12 \mathrm{~mm}$ como línea de división entre láminas y laminillas, se observa un evidente equilibrio porcentual entre ambas.

El retoque predominante es el simple $-58,33 \%-$, seguido del abrupto -30,56\%-, presente principalmente en geométricos, truncaduras, perforadores y taladros; existiendo cuatro piezas con retoque plano $-11,11 \%-$, solo o acompañado de los anteriores:

\footnotetext{
2 El carácter discriminante ha sido la longitud: superior a $50 \mathrm{~mm}$ en las láminas y $25 \mathrm{~mm}$ para la diferenciación entre laminitas y microlaminillas. En las piezas fracturadas el valor ha sido la anchura, siendo consideradas láminas aquellas que superan los $12 \mathrm{~mm}$ (Tixier, 1963).
}

un avivado de núcleo (Fig. 9, n. ${ }^{\circ}$ 6), un fragmento de lámina (Fig. 8, n. ${ }^{\circ}$ ), un denticulado sobre cristal de roca (Fig. 8, n. $^{\circ} 12$ ) y un denticulado con truncadura (Fig. 8, n. ${ }^{\circ} 20$ ).

Desde el punto de vista tipológico se observa una gran diversidad, con representación de todos los tipos que tradicionalmente caracterizan los conjuntos del Neolítico antiguo peninsular (Fortea et al., 1987). Los soportes laminares sin retocar o con retoques tradicionalmente atribuidos al uso son los elementos más abundantes (Fig. 8, n. $^{\text {os }} 1-4$ ), ya que representan el 61,45\% de la industria laminar, entre los que se incluyen tres láminas de cresta (Fig. 8, n. $^{\circ}$ 3). Igualmente, son frecuentes las lascas con retoques de uso (Fig. 8, n. ${ }^{\circ}$ 31) o con retoque denticulado (Fig. 8, n. ${ }^{\text {os }} 28-31$ ).

Las láminas, laminillas y microlaminillas retocadas (Fig. 8, n. ${ }^{\circ}$ 6) tienen un importante peso específico -25,64\%-, aunque muescas y denticulados (Fig. 8, n. ${ }^{\text {os }} 9-16$ ), frecuentes en contextos del Neolítico antiguo, constituyen el elemento retocado más abundante $-31,25 \%$-. Dentro de estos útiles destaca una muesca realizada sobre lámina de cresta con el borde avivado (Fig. 8, n. ${ }^{\circ}$ 9). Por otro lado, la importancia de perforadores, microperforadores y taladros es significativa $-10,26 \%-\left(\right.$ Fig. 8, n. $^{\text {os }}$ 24-27), y ligeramente inferior la de las truncaduras, oblicuas en todos los casos, que representan el 7,69\% del conjunto (Fig. 8, n. ${ }^{\circ} 21$ ). Una de ellas aparece sobre un soporte laminar de bordes retocados que presenta 'lustre de cereal', y otra sobre un denticulado (Fig. 8, n. ${ }^{\text {os }}$ 19-20). Los geométricos, integrados por dos segmentos (Fig. 8, n. ${ }^{\text {os }} 17-18$ ), uno de ellos fragmentado y en ambos casos con retoque abrupto, representan el 5,13\% del utillaje retocado, porcentaje bajo aunque propio de lugares de hábitat. Los diversos y útiles de sustrato representan un porcentaje algo superior al $10 \%$, lo que indica una importante herencia de carácter mesolítico. Dentro de estos, entre los que se encuentran un raspador con retoque simple tendente a plano (Fig. 8, n. ${ }^{\circ}$ 32) y tres avivados de núcleo (Fig. 9, n. $\left.{ }^{\text {os }} 4-6\right)$, tienen un peso predominante los buriles y microburiles (Fig. 8, n. ${ }^{\text {os }} 21-23$ ).

\subsection{Industria litica no extractiva}

La presencia de molinos de mano pone de manifiesto la realización de actividades de molienda en 

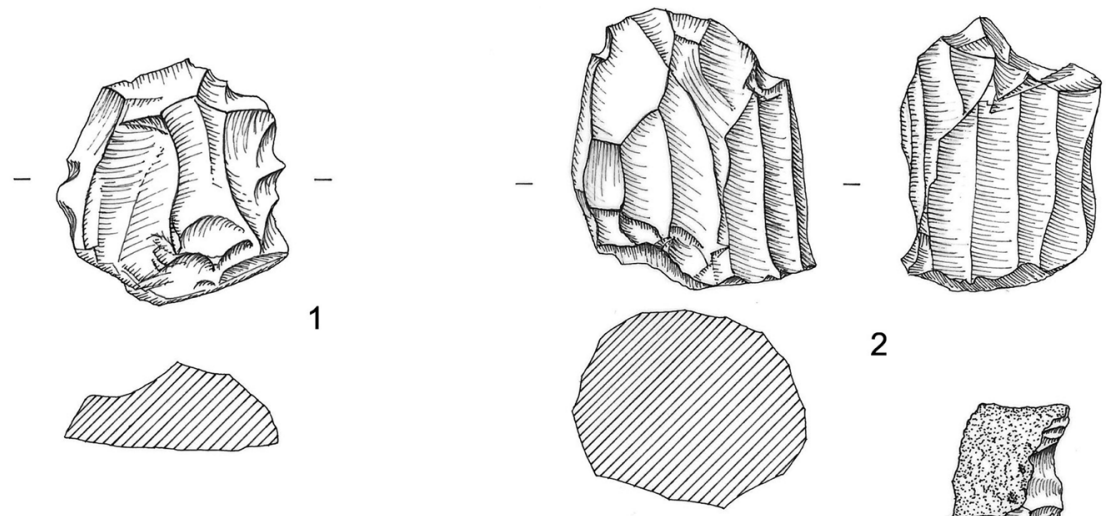

2
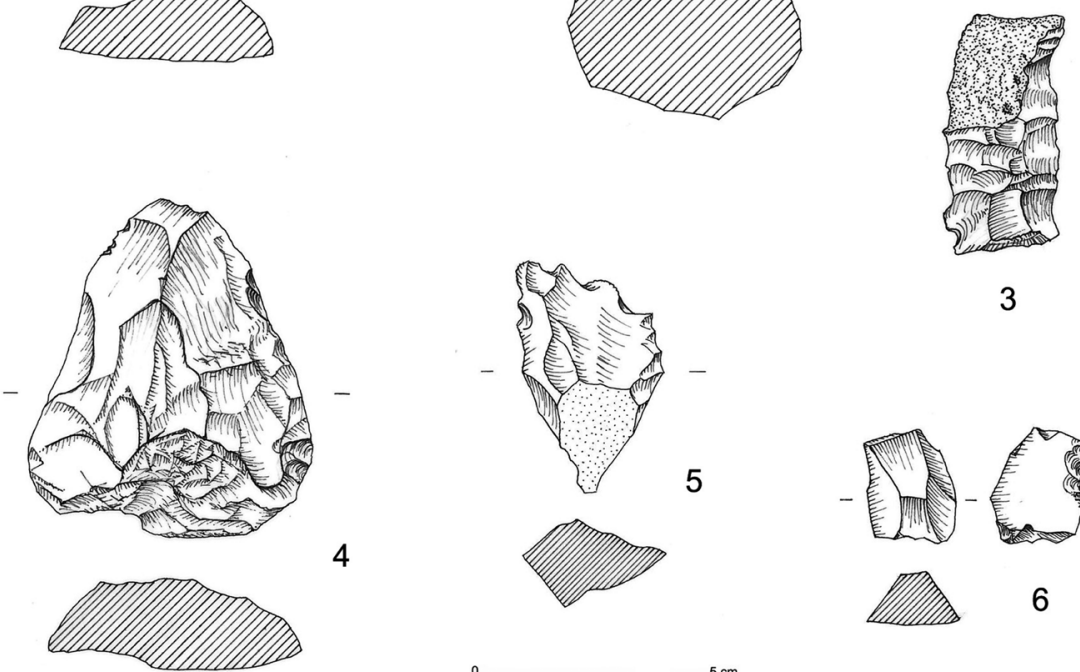

3

4
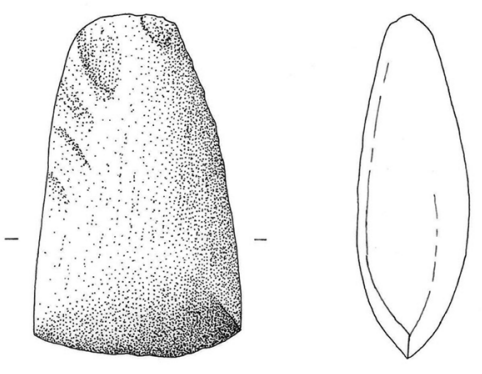

7
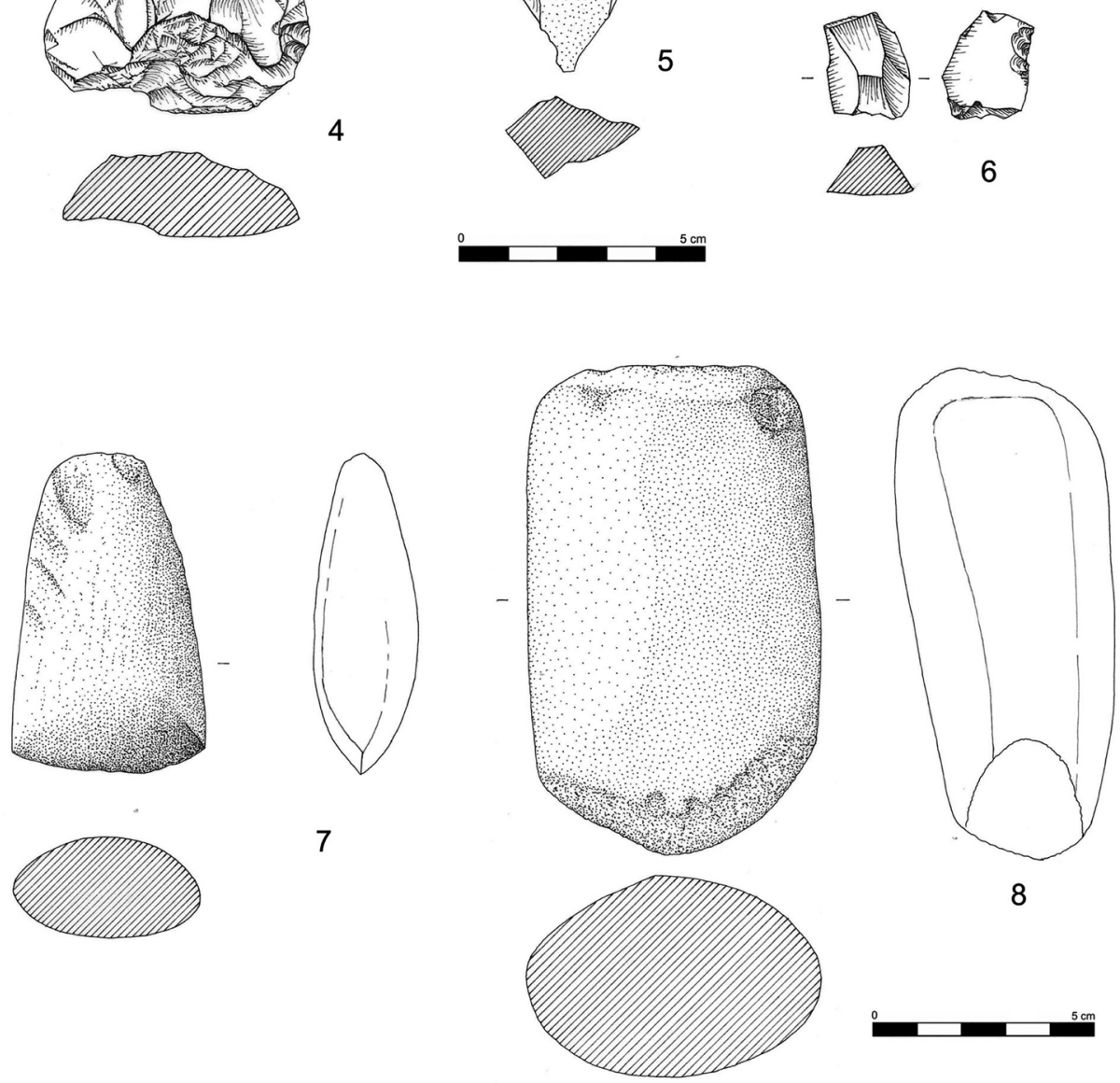

8

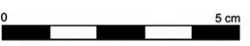

FIG. 9. Material litico: 1-2) núcleos; 3) lámina de cresta; 4-6) avivados; 7-8) industria litica pulimentada sobre ofita (dibujo: Belén Alonso). 
el poblado, pero también su utilización en relación al ritual funerario, ya que tres de las cuatro piedras recuperadas acompañaban a la inhumación de la estructura funeraria E-14.

Han sido recuperadas tres piedras pulimentadas de ofita: un fragmento, una azuela procedente de una fosa funeraria (Fig. 9, n. ${ }^{\circ} 7$ ) y un hacha pulimentada (Fig. 9, n. ${ }^{\circ}$ ). Sobre esta materia prima, abundante en la comarca de La Bureba, fueron trabajados preferentemente los útiles pulimentados neolíticos en Álava y La Rioja, siendo escasos en contextos habitacionales en cueva y más frecuentes en poblados al aire libre (Fernández Eraso, 2007-2008: 677). También ha sido recuperado un guijarro de cuarcita que parece haber sido utilizado como alisador.

Aunque no forma parte de la industria lítica, referimos en este apartado la documentación en varias estructuras de pequeños fragmentos de mineral de textura terrosa. A falta de análisis pormenorizados, podrían ser óxidos o hidróxidos de hierro utilizados como colorantes. El uso de este tipo de minerales ha sido atestiguado en forma de pequeños fragmentos en los niveles del Neolítico Antiguo del abrigo de Mendandia, en el Condado de Treviño (García, 2006: 511). En el cráneo del individuo inhumado en la fosa e-06 se han observado pequeñas y aisladas tinciones rojizas, de no más de $2 \mathrm{~mm}$, que podrían indicar el uso de colorantes durante el ritual funerario, sin que se pueda descartar, por otro lado, una transferencia ocasional de mineral.

\subsection{Restos óseos faunisticos}

Pese a que las estructuras excavadas están por lo general colmatadas por rellenos antrópicos que atrapan materiales domésticos de desecho, lamentablemente la presencia de restos óseos es muy reducida y relacionada con problemas de conservación. La escasa representatividad limita la posibilidad de analizar los hábitos alimenticios de los habitantes del poblado, y por lo tanto el peso específico que pudo tener la actividad ganadera y cinegética, pero proporciona información sobre algunas de las especies que formaron parte de la dieta.

Aunque los restos están presentes en 15 de las estructuras excavadas $-50 \%-$, mayoritariamente están integradas por pequeñas esquirlas de difícil atribución. Afortunadamente han sido recuperados otros restos que permiten ser atribuidos a grupos y especies concretas -cérvidos, équidos y suidos-, aunque la representatividad de las regiones óseas solo permite determinar un número mínimo de individuos -NMI- unitario en cada caso. En el registro documentado, la presencia mayoritaria de piezas dentales y astas debe ser puesta en relación con las mejores condiciones de conservación que suelen presentar estos restos.

Los cérvidos, presentes en tres estructuras, pertenecen a ciervo -Cervus elaphus-. Excepto un astrágalo, el resto se corresponde con piezas dentales y astas, destacando una cuerna completa de un individuo adulto. Los équidos, de taxón indeterminado -Equus spp-, están presentes en tres estructuras, representados por una epífisis de tibia de un individuo adulto, un molar y una falange. El único resto perteneciente a suido, que puede ser tanto doméstico como salvaje, es una falange.

\section{Restos óseos humanos}

Los huesos humanos están integrados por los restos esqueléticos de los dos individuos inhumados en las fosas funerarias E-06 y E-14, y por un molar recogido en la estructura E-11. Se trata de un primer molar mandibular sin reabsorción radicular, por lo que la pérdida no se produjo por la sustitución de la dentición decidua hacia los 10/11 años de edad, sino entre los 2 y los 6 años.

El estado de conservación de los dos individuos inhumados es muy deficiente, debido al deterioro sufrido por el paso del tiempo. El de la fosa E-06 conserva el cráneo, los huesos largos excepto el peroné derecho, metatarsos de la mano derecha y pequeños restos de cintura pélvica y costillas. El de la fosa E-14 el cráneo, los huesos largos, las clavículas, gran parte de los huesos de la mano izquierda, porciones de costillas, tarso derecho y algunos restos de cintura pélvica y de vértebras lumbares y coxales. En ambos casos son mujeres adultas cuya edad de muerte ha sido estimada en 40-45-E-06- y en 4856 ańos $-\mathrm{E}-14-^{3}$. Teniendo en cuenta que la edad

${ }^{3}$ La edad de muerte ha sido estimada principalmente a partir del grado de obliteración de las suturas craneales (Meindl y Lovejoy, 1985) y del desgaste dentario (Brothwell, 1987); y el sexo a partir de la morfología del cráneo y la escotadura ciática mayor (Buikstra y Ubelaker, 1994). 
de muerte de la población neolítica femenina a nivel peninsular se sitúa mayoritariamente entre los 21 y los 40 años, con porcentajes que varían entre el 58-94\%, las dos mujeres pertenecen al pequeño porcentaje $-6-13 \%-$ que superó esta edad ${ }^{4}$.

El grado de deterioro de los huesos largos ha impedido estimar la estatura, aunque a rasgos generales se puede definir como pequeña y asociada a una constitución grácil. Únicamente ha sido posible determinar algunos índices esqueléticos que, comparados con las poblaciones neolíticas estudiadas en Andalucía por S. A. Jiménez, revelan parámetros dentro del rango establecido y presentan pocas diferencias con respecto a la media absoluta. Con carácter general, se puede afirmar que las dos mujeres pertenecen al tipo mediterráneo grácil, que en las poblaciones neolíticas peninsulares es el más frecuente con un porcentaje en torno al $50 \%{ }^{5}$.

La mujer de la fosa E-14 presenta fuertes impresiones musculares en los huesos largos de las extremidades superiores, que denota una elevada actividad física en esta parte del cuerpo. Por el contrario, los índices pilástricos del fémur en los dos individuos son acordes con un estrés biomecánico bajo de las extremidades inferiores. A nivel patológico se observa un trauma en el hueso frontal, de forma ovalada y con unas dimensiones de $19 \mathrm{~mm}$ de longitud y
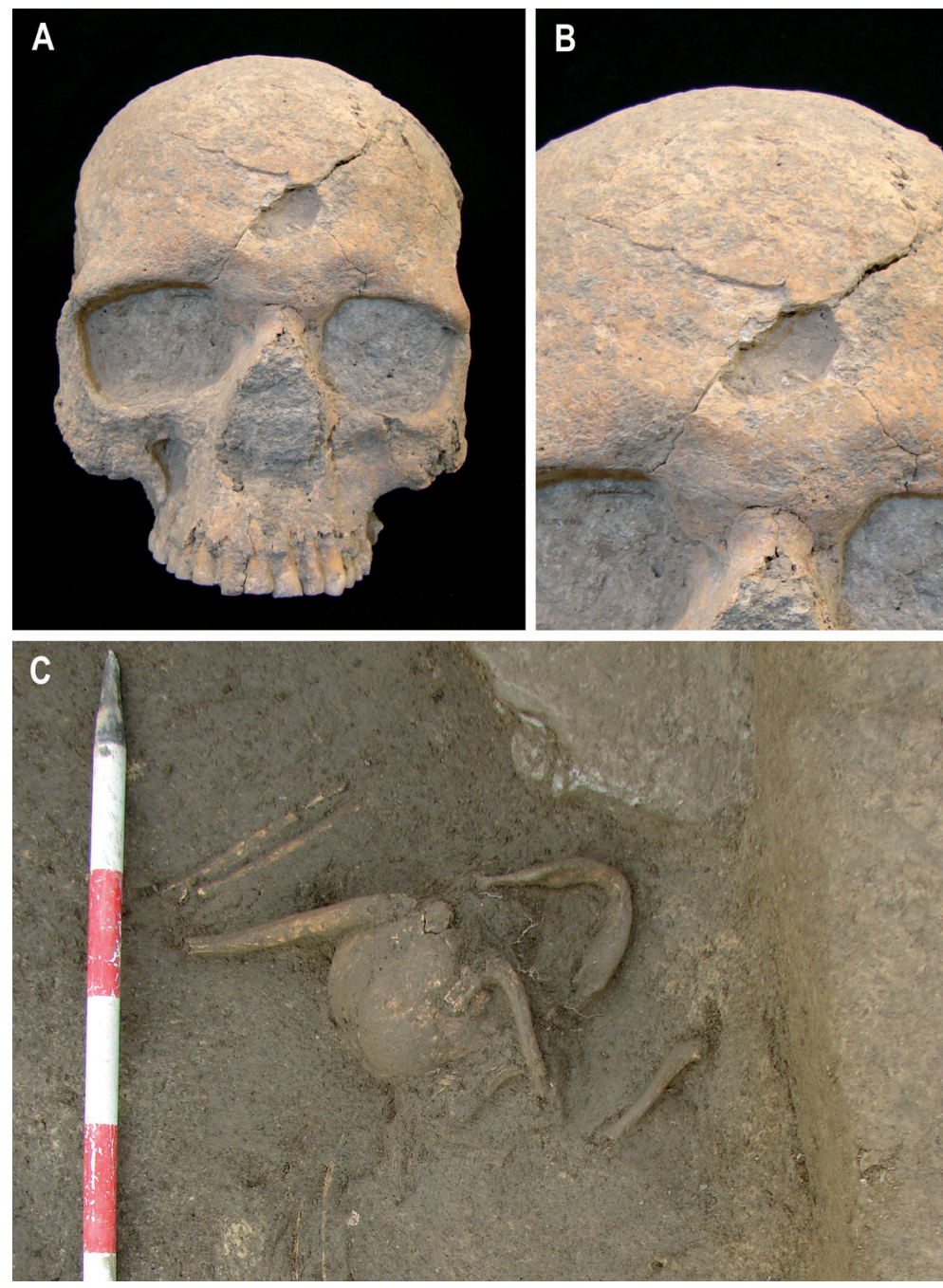

Fig. 10. Fosa funeraria E-14: A) cráneo femenino con traumatismo en el hueso frontal; B) detalle del trauma; C) conjunto óseo en el momento de la excavación.
$11 \mathrm{~mm}$ de anchura (Fig. 10). Se trata de un trauma obtuso por comprensión causado por un objeto de bordes romos, como por ejemplo una maza o un proyectil. Presenta amplias líneas de fractura radiantes que parten del punto de impacto, que en principio descartan la erosión selectiva u otros cambios tafonómicos e informan de la elevada energía

4 Jiménez Brobeil, S. A. (1987): Estudio antropológico de las poblaciones neoliticas y de la Edad del Cobre en la Alta Andalucía. Tesis doctoral inédita presentada en 1987 en la Univ. de Granada, pp. 312-313.

5 Ibidem, p. 495. con la que se produjo (Byers, 2005). No se observan signos de supervivencia, como reabsorción del hueso por osteólisis, por lo que la lesión debió resultar letal o la causa más probable de muerte. No es posible determinar si su origen fue accidental o intencional, pero se enmarca dentro del cada vez más numeroso registro neolítico europeo que pone de manifiesto tanto la existencia de violencia interpersonal -con conocidos ejemplos en Asparn-Schl o Talheim- como la realización de prácticas de manipulación de cadáveres -identificadas en Herxheim o Fontbregoua- (Schulting y Fibiger, 2012; Stecher et al., 
2013). A partir del Mesolítico parece que se produce un incremento de los restos óseos con signos de lesiones que ha sido vinculado con el sedentarismo y el incremento de la territorialidad, una evolución del comportamiento violento relacionado con el nuevo modelo de organización social y económico motivado por la competencia en la posesión de la tierra y la usurpación de los bienes ajenos (Roksandic, 2004) que parece consolidarse en el Neolítico.

\section{Análisis paleoambiental}

Sobre los rellenos antrópicos que amortizan cuatro silos de almacenaje-E-IO, E-I4, E-22 y E-26- se ha efectuado un análisis palinológico mediante sendas tallas por estructura obtenidas en la zona media y basal, evitando muestras de los revestimientos al poder contener pólenes antiguos ${ }^{6}$. Todas las muestras analizadas han alcanzado el umbral mínimo de representatividad por lo que ninguna de ellas ha sido considerada estéril en base a los convencionalismos que se aplican, presentando un óptimo grado de conservación. En la Figura 11 se representa el histograma del análisis con el grado de representatividad obtenido para árboles, arbustos, herbáceas, hidro-higrófilas y microfósiles no polínicos. Lo primero destacable es la gran homogeneidad tanto desde el punto de vista cualitativo como cuantitativo que presentan las muestras, lo que sugiere que los depósitos analizados se han visto sometidos a los mismos procesos de utilización y colmatación.

Las formaciones forestales del entorno del asentamiento estarían compuestas fundamentalmente por bosques de quercíneas perennifolias, posiblemente un encinar-carrascal. Se trata de una comunidad muy bien adaptada a los climas secos, que se desarrollan perfectamente en lugares de intensa insolación, con suelo escaso, pobre en nutrientes y pedregoso. Otra formación vegetal presente en el entorno serían los pinares de Pinus sylvestris; sus escasos requerimientos ecológicos permiten a este pino ocupar aquellos ambientes menos aptos para los caducifolios, como las zonas de mayor insolación, terrenos de menor retención hídrica, suelos menos desarrollados, etc. Por último, se

6 Análisis elaborado por el Grupo de Investigación, CCHS-Csic bajo la dirección de S. Pérez Díez y J. A. López Sáez. han identificado pólenes de taxones como Quercus caducifolio, que podría situarse en las zonas del fondo de valle con una mayor retención hídrica. Del mismo modo, en las cercanías del yacimiento se documenta la presencia de un bosque de ribera, en el que podrían situarse avellanos, alisos, fresnos, sauces y olmos.

Sin embargo, a pesar de la presencia de algunas masas forestales, se puede determinar que estas no alcanzaron grandes extensiones, estando el entorno circundante ocupado mayoritariamente por espacios abiertos. En concreto, el protagonismo de la vegetación de origen antrópico, como pastizales de gramíneas y otros elementos ruderales y nitrófilos, indica la intensa modificación del paisaje vegetal debido a las actividades humanas, algo patente en todas las muestras analizadas. Las evidencias palinológicas sobre el desarrollo de prácticas económicas en el entorno del asentamiento son igualmente rastreables. Por un lado, se ha constatado la existencia de elementos exigentes en nitrógeno como pastos antropozoógenos -Chenopodiaceae, Plantago lanceolata, Dipsacus fullonum-, así como microfósiles no polínicos de naturaleza coprófila -ascosporas fúngicas como Sordaria sp. -, que indican la existencia de ganado en las cercanías del yacimiento, aunque es difícil calibrar su importancia.

También se ha constatado el desarrollo de prácticas agrícolas, concretamente cultivo de cereales, si bien en porcentajes no demasiado elevados que oscilan entre el 1,5\% y el 3,2\%, cuestión que en su conjunto sí permite suponer la existencia de campos de cultivo en un área relativamente cercana al lugar de muestreo. En el caso del otro gran grupo de plantas cultivadas que frecuentemente se documentan en el registro paleobotánico, las fabáceas, se han identificado en todas las estructuras con valores cercanos al 5\%, si bien se trata de palinomorfos que no permiten reconocer su origen en poblaciones silvestres o cultivadas, aunque su alto porcentaje podría apuntar esta última hipótesis. Por otro lado, eventos erosivos asociados tanto a la antropización manifiesta del paisaje como posiblemente a las actividades agrícolas aquí desarrolladas se demuestran por la continua presencia de clamidosporas del hongo Glomus cf. Fasciculatum.

Los resultados evidencian un paisaje intensamente deforestado debido al desarrollo de prácticas económicas productivas, evidencias del desarrollo 


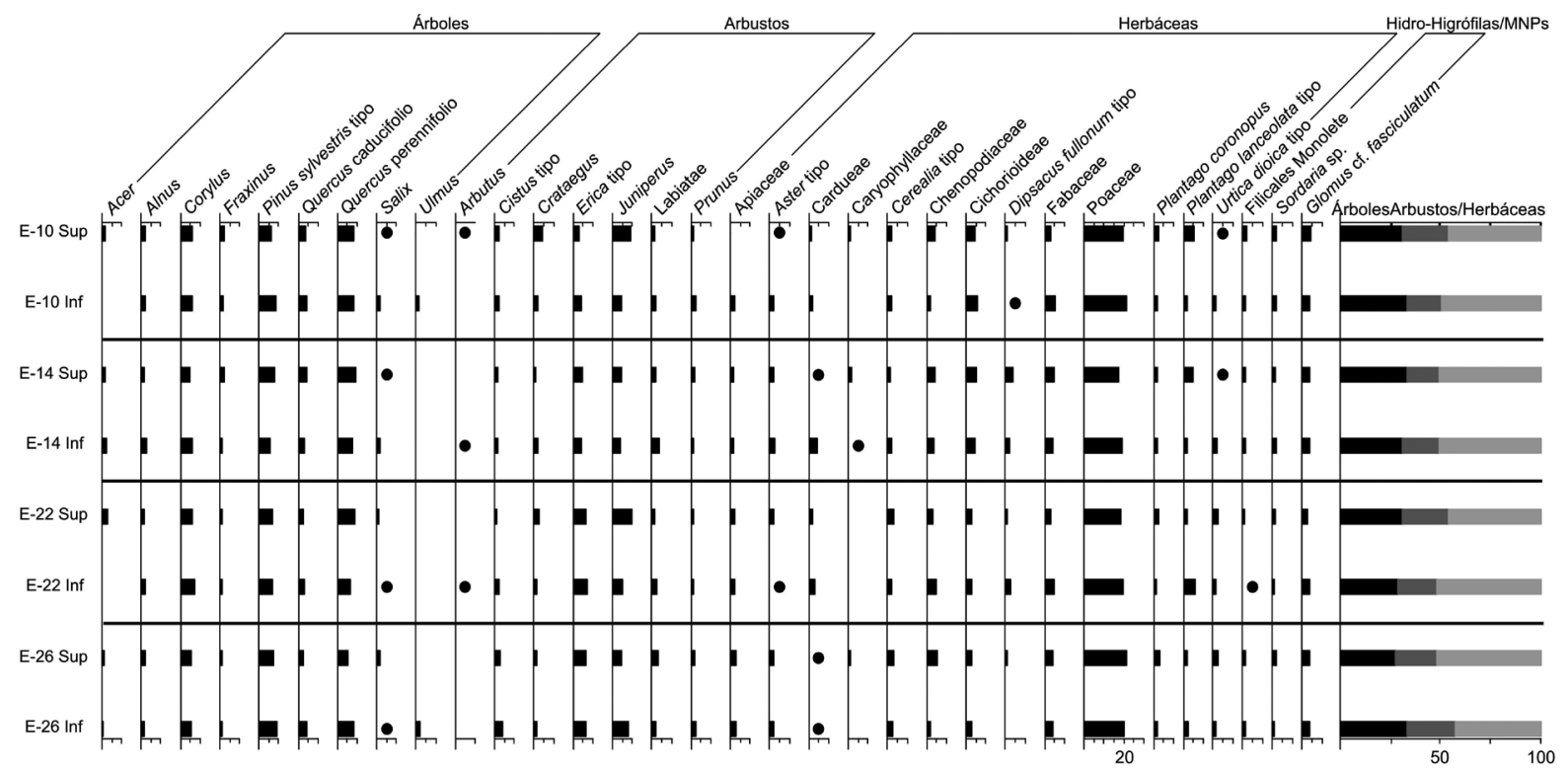

FIG. 11. Histograma palinológico del yacimiento de El Prado (Pancorbo, Burgos) (elaboración de CSIC, CCHS).

de actividades ganaderas como agrícolas que son motor de la intensa modificación del entorno del yacimiento.

Este marco ambiental puede ser puesto en relación con las condiciones de algunos yacimientos espacialmente cercanos y cronoculturalmente afines, como los niveles neolíticos I-III del abrigo de Mendandia, en Condado de Treviño ${ }^{7}$, y Miri 8 MIR2 I de la cueva de El Mirador, en el complejo de la Sierra de Atapuerca (Vergès et al., 2008). Las quercíneas perennifolias hacen progresivamente mayor acto de presencia, junto con pequeños bosquetes de pinar que tienden a reducirse en favor de espacios abiertos dominados por gramíneas y plantas de inspiración antrópica y taxones polínicos sinantrópicos que frecuentemente acompañan los grupos humanos. También en el yacimiento alavés de Peña Larga de Cripán, en la Sierra de Cantabria, continuidad de los Montes Obarenes, se ha obtenido secuencia polínica en las primeras fases de la ocupación del Neolítico antiguo -nivel IV-. En este caso el grado de humedad parece ser más importante,

7 Pérez Díaz, S. (2012): El paisaje vegetal durante la Prehistoria reciente en la vertiente mediterránea de Euskal Herría. Tesis doctoral inédita presentada en 2012 en upv/ EHU, pp. 253-254. ante la presencia de caducifolios y la cantidad de elementos hidro-higrófilos identificados ${ }^{8}$.

Las conclusiones ambientales que aporta el yacimiento El Prado $-5880 \pm 30$ BP- vienen a confirmar el aumento de la aridez que también se rastrea entre el 5900-5300 BP, segundo tramo de crecimiento de un espeleotema de la Galería de Estatuas de la Sierra de Atapuerca, momento en el que las condiciones ambientales oscilaban en torno a un "óptimo climático" (Martínez-Pillado et al., 2010: 100), templadas y húmedas con un aumento de la xericidad coincidiendo con otras regiones como la circunmediterránea (Buxó, 1996: 147).

\section{Valoración cronocultural}

La aproximación cronocultural del yacimiento ha sido realizada a partir del estudio de los materiales arqueológicos y del análisis radiocarbónico practicado sobre una muestra ósea del individuo inhumado en la fosa funeraria E-06. La muestra-Beta-366569, 13.16/Ue603- sitúa culturalmente el yacimiento en el Neolítico, con una datación convencional 5880 \pm 30 вр, que refiere un rango $4790-4720 \mathrm{cal} \mathrm{вс}$

8 Ibidem, pp. 257-258. 
-68\%- calibrado a $1 \sigma$ y $4820-4690$ cal вс $-95 \%-$ calibrado a $2 \sigma$-curva de calibración INTCAL09-.

La secuencia cronológica y cultural del Neolítico peninsular recibe diversas terminologías y acotaciones temporales según los autores y los límites geográficos. Si nos circunscribimos al ámbito biogeográfico en el que se inscribe el yacimiento, en una zona de tránsito entre la cuenca del Duero y alto valle del Ebro, el proceso de neolitización en la Meseta habría tenido lugar en el rango temporal 5500-5300 cal BC, siendo la fecha más antigua conocida hasta el momento la del yacimiento soriano de La Lámpara -5470-5320 cal вС- (Garrido et al., 2012: 481). En el alto valle del Ebro el inicio del proceso de neolitización hay que retrotraerlo doscientos años, según las fechas aportadas por el yacimiento burgalés de Mendandia (Alday et al., 2012: 295), con una datación 5640-5360 cal BC para el nivel II. La acotación cronológica del final del Neolítico antiguo parece mucho más controvertida, aunque en base a la última compilación realizada a nivel peninsular cabría situarlo en la segunda mitad del v milenio cal вс (Rojo et al., 2012), por lo que la fecha de El Prado se enmarca en el denominado Neolítico antiguo avanzado (Estremera, 2003: 188).

Si comparamos el rango temporal obtenido en El Prado con el registro radiocarbónico disponible en la cuenca del Duero y valle del Ebro (Rojo et al., 2012: 591-592, 600-602), en el primer caso únicamente la cueva segoviana de La Vaquera cuenta con dataciones calibradas que se solapan ( $\mathrm{GrN}-22929$ : 4721-4552; GrA-9228: 4934-4695), mientras que en el valle del Ebro encontramos un nutrido número de fechas afines como el nivel iv de Peña Larga (Beta-242782: 4700-4460), el nivel 2r de Abauntz (GrN-21010: 4790-4550), el nivel xv de Los $\mathrm{Hu}$ sos I (Beta-161181: 4820-4500), la fosa 2 de Paternanbidea (GrA-13675: 4970-4730) y el nivel 6 de Botiquería (GrA-13268: 5080-4800); todas ellas, excepto Abauntz, obtenidas a partir de muestras de vida corta. Cabe destacar que en el valle del Ebro únicamente la estación navarra de Paternanbidea es un yacimiento al aire libre, ya que el resto se corresponde con cuevas y abrigos, por lo que El Prado representa una importante aportación en este sentido al encontrarse geográficamente en la cuenca del Ebro.

En cuanto al conjunto de material arqueológico asociado, desde el punto de vista formal, tanto en lo relativo a la diversidad como a la tipología de perfiles, el conjunto cerámico presenta rasgos compartidos con otros yacimientos del Neolítico antiguo de ambas cuencas (García et al., 2011: 87), destacando la abundancia de elementos de prensión, la presencia de recipientes de fondo cónico y un porcentaje de recipientes con tratamientos superficiales a base de aguadas o almagras que remite a la subfase Iв de La Vaquera (Estremera, 2003: 70, 95). Sin embargo, si nos atenemos al repertorio decorativo (Alday, 2003: 77; García et al., 2011: 90 y ss.), apreciamos una clara conexión con el valle del Ebro, destacando el predominio de la utilización en los recipientes de una sola técnica, siendo la impresa mayoritaria en porcentajes absolutos. Esto mismo se observa en el nivel iv de Peña Larga, en la capa XV de Los Husos i y en el nivel viI de Los Husos II (Fernández Eraso, 2007-2008: 676), que han proporcionado fechas radiocarbónicas similares a la nuestra y que se encuentran en ámbitos geográficos cercanos. Además, cabe destacar la elevada presencia de cordones lisos, ausentes o escasamente representados en los yacimientos de la Meseta pero abundantes en el valle del Ebro. Por último, en contraposición con lo que sucede en la cuenca del Duero, la técnica incisa está peor representada, con escasos ejemplos acanalados y la testimonial asociación incisión-impresión. Sin embargo, una pieza decorada con motivos incisos horizontales y verticales asociados a un asa de cinta, en un estilo considerado como una peculiaridad meseteña (García et al., 2011: 101), relaciona El Prado con yacimientos como La Vaquera, La Lámpara o La Velilla, demostrando que no es ajeno a las peculiaridades culturales de la Meseta. Por último, la presencia de una pieza decorada con la técnica del boquique incluye al yacimiento en el conjunto de estaciones neolíticas que han proporcionado materiales arqueológicos en este sentido, dentro del ámbito geográfico recientemente definido para su distribución y enmarcado cronológicamente en un momento en el que el uso de la técnica comienza a descender (Alday, 2011: 76, 79).

También la industria lítica extractiva es compatible con los primeros estadios del Neolítico de ambas cuencas (Alday et al., 2012: 307; Garrido et al., 2012: 479). Tecnológicamente se observa la marcada tendencia a la utilización de técnica laminar frente al lascado, destacando entre los soportes 
enteros la escasa representación de láminas frente al casi exclusivo de laminillas y microláminas, si bien el uso de soportes acortados mediante fracturación voluntaria es predominante. Dentro de la gran diversidad tipológica de útiles, encontramos un importante porcentaje de soportes laminares no retocados o con retoques tradicionalmente atribuidos al uso, y la significativa presencia de perforadores, taladros y útiles de sustrato. Por otro lado, también están representados los característicos elementos de hoz y los geométricos, en concreto segmentos, el tipo predominante en el Neolítico antiguo y particularmente presente en la zona occidental del valle del Ebro (Alday et al., 2012: 307), aunque con retoque abrupto y no a doble bisel que es el característico de los primeros estadios.

\section{Interpretación y contextualización del yacimiento}

El poblado neolítico de El Prado se asimila con un pequeño lugar de habitación, cuya extensión superficial difícilmente pudo alcanzar 0,3 ha de extensión. El patrón de asentamiento se acomoda a los estándares de los poblados al aire libre del valle del Ebro (Alday et al., 2012: 302) y de la cuenca del Duero (Garrido et al., 2012: 469), contando en este caso con la inmediatez de un corredor natural de comunicación como también sucede en el soriano valle de Ambrona. Sin embargo, a nivel comarcal se conocen otros asentamientos del Neolítico antiguo fuera de contextos de fondo de valle, como el poblado del Alto de Rodilla en Monasterio de Rodilla (Burgos), emplazado en un borde de páramo junto al mismo corredor natural, a $25 \mathrm{~km}$ al o9. En este sentido, la amplia variedad de hábitats que ofrece el entorno de Pancorbo permite dibujar una todavía pequeña red de asentamientos neolíticos de gran variabilidad tanto en cavidad, como Cueva Vallojera en Ameyugo (Campillo, 1996), como al aire libre, siendo el caso de Onzarán y Fuente Galindo de Cubo de Bureba, atribuidos a un momento

9 Alonso, C. y Jiménez, J.: "El Neolítico en el corredor Alto Ebro-Alto Duero: dos hallazgos funerarios del Neolítico antiguo y reciente en Monasterio de Rodilla (Burgos)". En Actas del V Congresso del Neolítico Peninsular (Lisboa, 2011). Lisboa: Univ. de Lisboa, pp. 504-510, en prensa. más avanzado del Neolítico reciente ${ }^{10}$, este último más extenso y estructurado desde el punto de vista habitacional.

$\mathrm{Su}$ vigencia en el tiempo, por otro lado, no debió ser muy prolongada, ya que todos los registros obtenidos -arquitectura de los silos, materiales arqueológicos, registro polínico, etc.- no ofrecen apenas variabilidad, al tiempo que el registro paleoambiental sugiere que fue ocupado de forma continua y no estacional o recurrente. Se trataría posiblemente de un asentamiento de tipo disperso en respuesta a una sociedad tribal segmentaria, de carácter comunal, articulada en unidades familiares de producción que cooperan en labores de agricultura de roza, pastoreo y cinegético-recolectora, al hilo del patrón que se propone en el contexto neolítico para la Sierra de Atapuerca y su aledaño valle del Arlanzón (Marcos, 2006: 246-254).

El registro paleoambiental obtenido permite determinar esa economía diversificada de los moradores del poblado. Aunque los restos de fauna conservados son escasos, cabe señalar la importante presencia de ciervo-Cervus elephus-, que da cuenta no solo de la significativa actividad venatoria como recurso de subsistencia, sino también de la configuración del paisaje vegetal. La actividad ganadera igualmente queda manifiesta en el repertorio polínico por asociación a determinados elementos exigentes en nitrógeno como pastos antropozoógenos, así como microfósiles no polínicos de naturaleza coprófila.

En cuanto a la práctica agrícola, y a falta de estudios carpológicos, la existencia de silos de almacenamiento y de elementos de utillaje asociados a su procesado, como molinos de mano y dientes de hoz, informa per se de esta actividad, que a juzgar por el registro polínico debió realizarse en el entorno inmediato al poblado. La presencia de polen de fabáceas con valores elevados, próximos al 5\%, y de cereales alcanzando valores máximos del 3,2\% de la muestra contribuye a constatar el cultivo como un recurso consolidado, aspecto corroborado también por la antropización manifiesta del paisaje por eventos erosivos o de la práctica agrícola.

El medio ambiente en el momento de la ocupación del yacimiento se inscribe dentro de los patrones

10 Cronos s.c. (2012): Sondeos arqueológicos en el yacimiento "Fuente Galindo" de Cubo de Bureba (Burgos). Informe inédito. 
generales que concurren en el Neolítico antiguo peninsular, ofreciendo en este caso un mayor espectro de antropización frente a estaciones ligeramente más antiguas de su entorno, como Mendandia y El Mirador, consecuencia del avance progresivo en el desarrollo de las comunidades neolíticas, quizás con un gradiente mayor de aridez ante la presencia mayoritaria de quercíneas perennifolias y pequeños pinares en los inicios del óptimo climático que se postula para el rango temporal 5900-5300 вр.

Por su especial significación en el yacimiento cabe destacar la existencia de dos fosas funerarias que representan una importante aportación al conocimiento de las prácticas funerarias durante el Neolítico antiguo, no solo porque vienen a completar el exiguo mapa y la desigual distribución de hallazgos documentados en la Península hasta finales del v milenio cal вс (Garrido et al., 2012: 145, $151)$, sino también por incorporar interesantes novedades relacionadas con el ritual. El enterramiento en fosa al aire libre durante el Neolítico alcanza el mayor número de manifestaciones en el noreste peninsular, con enterramientos fundamentalmente individuales y escasos ajuares, entre ellos molinos y piedras pulimentadas; existiendo fosas datadas en la segunda mitad del v milenio cal BC que cuentan con un acceso lateral por el que se accede a la cámara sepulcral (Gibaja, 2004: 14), con las que encontramos ciertas similitudes. Sin embargo, estas manifestaciones en el alto valle del Ebro y en la Meseta Norte son mucho más escasas. Las más próximas a El Prado corresponden con las fosas individuales burgalesas de Alto de Rodilla y El Hoyo, en Monasterio de Rodilla, de finales del vi milenio y finales del $\mathrm{v}$ cal $\mathrm{BC}$, respectivamente ${ }^{11}$; en el alto valle del Ebro, las necrópolis navarras de Los Cascajos, con fechas centradas mayoritariamente a finales del vi milenio pero también en la segunda mitad del v, y de Paternanbidea, entre finales del VI milenio y principios del v cal вС (García et al., 2011: 137). En ambos yacimientos navarros también han sido recuperados molinos de mano asociados a los contextos funerarios.

Los testimonios de El Prado, por lo tanto, vienen a conectar ambas zonas biogeográficas a nivel de distribución espacial, siendo las manifestaciones funerarias de este tipo más próximas a las regiones

11 Alonso y Jiménez: op. cit. n. 9. de La Rioja y La Rioja Alavesa, que hasta la fecha carecen de registro (Fernández, 2010). Cabría hacer una mención especial al yacimiento navarro de $\mathrm{Pa}$ ternanbidea, en particular por las conexiones culturales que comparte en relación a determinados aspectos rituales, más concretamente los relacionados con la manipulación de los cuerpos (García, 2007); una práctica excepcional en el territorio analizado, que cobra un especial sentido si tenemos en cuenta que este yacimiento ha deparado una de las fechas más afines a la nuestra. Otras conexiones las encontramos con la inhumación individual soriana de La Lámpara, una mujer de avanzada edad que apareció acompañada de restos óseos faunísticos y diferentes materiales asociados a la actividad agrícola, como en nuestro caso. Los restos de fauna han sido relacionados con el banquete funerario, mientras que los materiales asociados a la actividad agrícola -entre ellos molinos de mano y láminas con 'lustre de cereal', como en El Prado- podrían tener una interpretación simbólica relacionada con el ciclo de la cosecha y el procesado de sus productos (Rojo et al., 2008: 394-397).

El yacimiento El Prado incorpora, en definitiva, los aspectos más significativos de los lugares de hábitat del Neolítico Antiguo Avanzado al aire libre, siendo un eslabón del conocimiento actual entre las regiones biogeográficas de la Meseta y el valle del Ebro, de forma coherente a su situación geográfica y al corredor natural junto al cual se localiza.

\section{Bibliografía}

Alday, A. (2003): "Cerámica neolítica en la región vascoriojana: base documental y cronológica”, Trabajos de Prehistoria, 60 (1), pp. 53-80.

Alday, A. (2011): "El dominio de la cerámica boquique: discusiones y técnicas cronoculturales". En BERNABEU, J.; Rojo, M. A. y Molina, L. (coords.): Las primeras producciones cerámicas: el VI milenio cal AC en la Península Ibérica. Saguntum Extra-12, pp. 65-81.

Alday, A.; Montes, L. y Bladellou, V. (2012): "Cuenca del Ebro”. En Rojo, M. A.; Garrido, R. y García, I. (coords.): El Neolitico en la Península Ibérica y su contexto europeo. Madrid: Cátedra, pp. 291-331.

Alonso, C. y Jiménez, J. (2012): “El tránsito Protocogotas/Cogotas I Pleno en el límite de la zona nuclear: análisis comparativo de tres yacimientos de la comarca del Arlanzón (Burgos)". En Rodríguez, J. A. y FerNÁNDEZ, J. (eds.): Cogotas I. Una cultura de la Edad del 
Bronce en la Península Ibérica. Valladolid: Univ. de Valladolid, pp. 361-376.

Armentano i Oller, N. (2012): "L’antropología prèvia al laboratori. Comprendre la tafonomía de los restos humanes". En Rituals i simbolismes, de la Prehistòria a l'actualitat. Actes de la Jornada de Treball XV (Artesa de Segre, 2010). Sant Martí de Maldà: Grup de Recerques de les Terres de Ponent, pp. 101-112.

Bernabeu, J. (2010): "El mundo funerario entre el vi y el II milenio a.C.". En Pérez, C. y Soler, B. (coords.): Restos de vida y muerte. La muerte en la Prehistoria. Valencia: Museo de Prehistoria de Valencia, pp. 45-54.

Brothwell, D. R. (1987): Desenterrando huesos. La excavación, tratamiento y estudio de restos del esqueleto humano. Madrid: FCE.

Buikstra, J. E. y Ubelaker, D. H. (eds.) (1994): Standards for data collection from human skeletal remains. Proceedings of a Seminar at the Field Museum of Natural History Organized by J. Haas. Arkansas Archaeological Survey Research Series n. ${ }^{\circ}$ 44. Fayetteville.

Buxó i Capdevila, R. (1996): Arqueología de las plantas. Barcelona: Crítica.

Byers, S. N. (2005): Introduction in forensic anthropology. Boston: Allyn and Bacon.

Campillo, J. (1996): "La arqueología de la Cueva Vallojera. Ameyugo", Estudios Mirandeses, xv, pp. 23-39.

Duday, H. (2009): The archaeology of the dead. Lectures in Archaeothanatology. Oxford: Oxbow Books.

Estremera, S. (2003): Primeros agricultores y ganaderos de la Meseta Norte: el Neolítico de la Cueva de La Vaquera (Torreiglesias, Segovia). Valladolid: JcyL.

Fernández Crespo, T. (2010): "Caracterización antropológica y tratamiento funerario de las poblaciones del Neolítico a la Edad del Bronce en la comarca de la Rioja: estado de la cuestión", Munibe, xx, pp. 17-24.

Fernández Eraso, J. (2007-2008): "La secuencia del Neolítico en La Rioja Alavesa desde su origen hasta las primeras edades del metal", Veleia, 24-25, pp. 669-687.

Fortea, J.; Martín Oliver, B. y Juan, J. (1987): "La industria lítica tallada del Neolítico antiguo en la vertiente mediterránea de la Península Ibérica”, Lucentum, vI, pp. $7-31$.

García Díez, M. (2006): "Los materiales colorantes del depósito arqueológico de Mendandia (Sáseta, Condado de Treviño, Burgos)". En AldaY, A.: El legado arqueológico de Mendandia: los modos de vida de los últimos cazadores en la Prehistoria de Treviño. Valladolid: JCyL, pp. 511-518.

García Gazólaz, J. (2007): "Los enterramientos neolíticos del yacimiento de Paternanbidea (Ibero)". En Hurtado, M. A.; Cañada, F.; Sesma, J. y García, J. (coords.): La tierra te sea leve: arqueología de la muerte en Navarra. Pamplona: Gob. de Navarra, pp. 59-65.

García Gazólaz, J.; Sesma, J.; Rojo, M. A.; Alday, A.; Garrido, R. y García Martínez de Lagrán, I. (2011): "Los Cascajos (Los Arcos, Navarra)". En Bernabeu, J.;
Rojo, M. A. y Molina, L. (coords.): Las primeras producciones cerámicas: el VI milenio cal AC en la Península Ibérica. Saguntum Extra-12, pp. 135-141.

García Martínez de Lagrán, I.; Garrido, M.; Rojo, M. A.; Alday, A.; García Gazólaz, J. y Sesma, J. (2011): "Cerámicas, estilo y neolitización: estudio comparativo de algunos ejemplos de la Meseta Norte y Alto Valle del Ebro". En Bernabeu, J.; Rojo, M. A. y Molina, L. (coords.): Las primeras producciones cerámicas: el VI milenio cal AC en la Peninsula Ibérica. Saguntum Extra-12, pp. 83-104.

Garrido, R.; Rojo, M. A.; García Martínez de Lagrán, I. y Tejedor, C. (2012): "Cuenca del Duero". En Rojo, M. A.; Garrido, R. y García Martínez de Lagrán, I. (coords.): El Neolitico en la Peninsula Ibérica y su contexto europeo. Madrid: Cátedra, pp. 463-505.

Garrido, R.; Rojo, M. A.; Tejedor, C. y García Martínez de Lagrán, I. (2012): "Las máscaras de la muerte: ritos funerarios en el Neolítico de la Península Ibérica”. En Rojo, M. A.; Garrido, R. y García Martínez de Lagrán, I. (coords.): El Neolitico en la Península Ibérica y su contexto europeo. Madrid: Cátedra, pp. 143-171.

Gibaja, J. F. (2004): "Prácticas funerarias durante en Neolítico en Cataluña", Mainake, xxvı, pp. 9-27.

Marcos, F. J. (2006): La Sierra de Atapuerca y el Valle del Arlanzón. Patrones de asentamiento prehistóricos. Burgos: Dossoles.

MÁrquez, J. (2001): “De los campos de silos a los 'agujeros negros': sobre fosas, depósitos y zanjas en la Prehistoria Reciente del Sur de la Península Ibérica”, SPAL, 10, pp. 207-220.

Martínez-Pillado, V.; Aranburu, A.; Yusta, I. y ArsuaGA, J. L. (2010): "Clima y ocupaciones en la Galería de Estatuas (Atapuerca, Burgos) en los últimos 14000 años: relatos de una estalagmita", Munibe, 61, pp. 89-102.

MeindL, R. S. y Lovejoy, C. O. (1985): "Ectocranial suture closure: A revised method for the determination of skeletal age death and blind tests of its accuracy", American Journal of Physical Anthropology, 68, pp. 57-66. http://dx.doi.org/10.1002/ajpa.1330680106

Metcalf, P. y Huntinton, R. (1991): Celebrations of Death: The Anthropology of mortuary ritual. Cambridge: Cup.

Rojo, M. A.; Garrido, R. y García Martínez de LaGRÁN, I. (coords.) (2012): El Neolitico en la Peninsula Ibérica y su contexto europeo. Madrid: Cátedra.

Rojo, M. A.; Garrido, R.; García Martínez de Lagrán, I. y TEJEDOR, C. (2008): Los primeros agricultores y ganaderos del interior peninsular: diez años de investigaciones en el valle de Ambrona (Soria). Soria: Ayuntamiento de Miño de Medinaceli.

RoKsANDIC, M. (2004): "Introduction: how violent was the Mesolithic, or is there a common pattern of violent interactions specific to sedentary hunter-gatherers?". En Roksandic, M. (ed.): Evidence and meaning of 
violent interactions in Mesolithic Europe. BAR Int. Ser., 1237. Oxford: Archaeopress, pp. 1-17.

Schulting, R. y Fibiger, L. (2012): Sticks, stones, and broken bones: Neolithic violence in a European perspective. Oxford: oup.

Stecher, M.; Schlenker, B. y Alt, K.W. (2013): “Die Scherbenpackgsgräber”. En Meller, H. (ed.): 3300 BC. Mysteriöse Steinzeittote und ihre Welt. Landesmuseum für Vorgeschichte, Nünnerich-Asmus Velag \& Media. Mainz, pp. 282-289.

TARriño, A. (2006): El sílex en la Cuenca Vasco Cantábrica y Pirineo Navarro: caracterización y su aprovechamiento en la Prehistoria. Monografías del Centro de Investigación y Museo de Altamira. Madrid: Ministerio de Cultura.

Tixier, J. (1963): Typologie de l'Epipaléolitique du Maghreb. Mémoires du Centre de Recherches anthropologiques, préhistoriques et ethnologiques, 2. Paris.

Vergès, J. M.; Alluì, E. y Angelucci, D. E. (2008): “Los niveles neolíticos de la cueva de El Mirador (Sierra de Atapuerca, Burgos): Nuevos datos sobre la implantación y el desarrollo de la economía agropecuaria en la Submeseta Norte”. En Hernández, M. S.; Soler, J. y López, J. A. (eds.): IV Congreso del Neolitico Peninsular (Alicante, 2006). Alicante: MARQ, vol. I, pp. 418-427. 